\title{
The Oculocardiac Reflex: A Review
}

\author{
Robert W Arnold (D) \\ The Alaska OCR Study, Alaska Blind \\ Child Discovery, Alaska Children's EYE \& \\ Strabismus, Anchorage, AK, 99508, USA
}

Video abstract

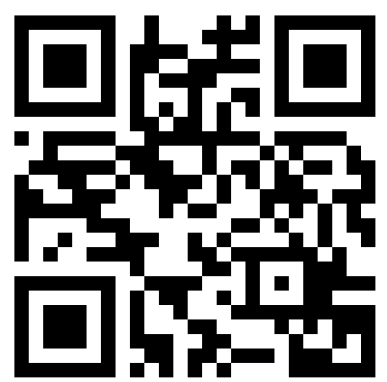

Point your SmartPhone at the code above. If you have a $Q R$ code reader the video abstract will appear. Or use: https://youtu.be/jgkgShlhvo0

Correspondence: Robert W Arnold The Alaska OCR Study, Alaska Blind Child Discovery, Alaska Children's EYE \&

Strabismus, 3500 Latouche \#280,

Anchorage, AK, 99508, USA

Tel + | 90756|-1917

Fax + I 907563-5373

Email eyedoc@alaska.net
Background: A typical oculocardiac reflex (OCR) is a moderate trigemino-vagal bradycardia elicited by tension on an extraocular muscle (EOM) during strabismus surgery; however, many other orbital stimuli can elicit cardiac slowing including retinopathy of prematurity examination.

Methods: World literature related to trigeminovagal and oculocardiac reflex covering over 15,000 patients including 51 randomized clinical trials and case reports are analyzed and reviewed. Under an ongoing observational trial in Alaska, anesthetic, patient and surgical influences on routine strabismus surgery using prospective, uniform EOM tension are compared seeking sufficient sample size to characterize this individually widely variable cardiac response.

Results: With adequate sample size, and emphasizing clinical studies controlling type of EOM, muscle tension amount and duration, anticholinergic and opioid medications, the following augment OCR; rapid-acting opioids and dexmedetomidine while OCR is reduced in older patients, the right eye, less EOM tension, deeper inhaled agents, hypocarbia, anticholinergic medications and orbital block. In re-operations, the former are relatively poor predictors of subsequent OCR.

Conclusion: Profound bradycardia can occur in almost $10 \%$ of strabismus surgery cases without anticholinergic preventive measures, but reliable prediction of OCR remains elusive. With foreknowledge and careful anesthetic monitoring of the patient before EOM manipulation, residual adverse sequelae from OCR are fortunately very rare. Despite well over a century of experience, the teleology for this occasionally dramatic cardiac response to eye surgery is still not known.

Keywords: strabismus surgery, trigeminovagal reflex, bradycardia, asystole

\section{Introduction}

Intending to safely restore binocularity and reverse childhood vision impairment from strabismic amblyopia, the surgeon gently approaches the medial rectus muscle. The anesthesiologist has already guided the otherwise healthy patient through a smooth induction and inserted a secure airway. Oxygenation, blood pressure and heart rate are stable as evidenced by a background, high-pitched regular cadence of the pulse oximeter. The smooth, thin tip of the Jameson muscle hook slides under the muscle insertion allowing the assistant to abduct the globe. Immediately, the heart slows to an electrocardiograph R-R interval of more than 4 seconds with loss of p-wave. The average of the patient's, the surgeon's, and the anesthesiologist's heart rates remains constant through the ordeal.

There have been a few prior efforts to review the oculocardiac reflex. vanBrocklin et al wrote a brief review of oculocardiac reflex published in $1982 .{ }^{1}$ Scheiermann et al reviewed 9 randomized trials concerning anesthetic impacts on 
OCR finding two limited conclusions: propofol produced more OCR ( 2 studies combined for 257 patients) and volatile anesthetic produced more postoperative nausea and vomiting (PONV). ${ }^{2}$ Despite 9 RCTs the limited conclusions seemed to stem from "clinical or statistical heterogeneity among the studies." ${ }^{2}$ Dunville and Kramer have started an OCR review web page. ${ }^{3}$ The practicing strabismus surgeon and ophthalmic anesthesiologist will benefit from an evidence-based review on how they can cooperate to make surgery safe and efficient, especially for strabismus patients.

Manipulation of various visceral organs can elicit reflex bradycardia. ${ }^{4}$ The oculocardiac reflex (OCR) is no exception, however, when profound it usually comes as a surprise. The vagal bradycardia is triggered by trigeminal nerve stimulation around the orbit and specifically tension on an extraocular muscle tendon. OCR is highly variable from one case to the next sometimes even producing tachycardia but usually a mild-to-moderate, brief sinus bradycardia. ${ }^{3}$ However, in less than $10 \%$ of cases the heart rate can drop to less than half with A-V nodal, junctional rhythm or even premature ventricular beats. Sometimes the bradycardia is also accompanied by arrest of spontaneous respiration. ${ }^{5}$

When profound OCR strikes, what should the strabismus surgical team do? Is treatment more harmful than the bradycardia? ${ }^{6}$ In very young patients, cardiac output is primarily rate-dependent so bradycardia leads to hypoperfusion. In older patients, sudden bradydysrhythmias may persist or be associated with counterproductive compensatory adrenergic responses. The literature has reports of death associated with oculocardiac reflex during strabismus or retinal surgery. ${ }^{7,8}$ A 17-year-old strabismus patient had IV atropine, halothane and nitrous oxide, but tension on the lateral rectus produced prolonged OCR less than $50 \%$ - then cyanosis leading to ICU and death with subsequent finding of viral myocarditis. ${ }^{9}$ Asystole and pulmonary edema have been reported associated with infestation of an extraocular muscle..$^{10}$ Myocardial infarction has been reported associated with OCR treatment. ${ }^{11}$ Death during strabismus surgery appears to be rare. ${ }^{12} \mathrm{~A}$ recent 10-year summary of anesthesia-related claims through OMIC insurance in USA had only one claim from strabismus surgery and only 5 with general anesthesia out of 50 total. $^{13}$

Over 110 years ago, one researcher named Aschner in Germany ${ }^{14}$ and another named Dagnini in Italy ${ }^{15}$ independently described a vagal reflex elicited from manipulation of the eyes. Six years later, Petzetakis in France described cardiac and respiratory changes elicited from the eyes. ${ }^{16}$ An oculocardiac reflex during enucleation was reported in the American literature in $1935 .{ }^{17}$ In 1957 in the first of two papers, Kirsch et al reported 30\% incidence of OCR defined as any electrocardiograph (ECG) change in 50 adult and pediatric patients during various eye surgical procedures including enucleation, and that OCR could be blocked by retrobulbar local anesthetic. ${ }^{18}$

Wide variability: From a baseline of $72 \mathrm{bpm}$, three different patients might have very different heart rate responses to identical extraocular muscle tension; the first might have a profound OCR dropping rapidly to 30 bpm (two second R-R interval with loss of p-wave), another might have average OCR response dropping slowly to $60 \mathrm{bpm}$, while the third might have no change, or even mild tachycardia in response to strabismus surgical muscle isolation.

Decades ago, a prospective, observational research project was designed to eventually achieve sufficient sample size to satisfactorily answer important questions about OCR despite the wide intra-subject variability in strabismus surgery patients (Figure 1). Information from The Alaska OCR Study will inform this careful literature analysis and review of world literature pertaining to the oculocardiac reflex from which clinically pertinent conclusions can be drawn. A well-informed team led by the ocular surgeon and anesthesiologist will be prepared to provide the safest care whenever a profound oculocardiac reflex is encountered.

\section{Methods}

The Alaska OCR study: From 1992 through 2020, consecutive cases of strabismus surgery were prospectively documented under an observational protocol approved by the Institutional Review Board of Providence Hospital (Clinical Trial NCT04353960). As an observation of typical, clinical anesthetic and strabismus surgery practice, written consent was not required. The Alaska OCR Study protocol was modeled after the 1988 Indiana University protocol that recorded conventional anesthetic agent and monitoring variables utilizing a standardized extraocular muscle (EOM) tension identical to typical rectus muscle surgery. ${ }^{19}$ The study complies with the Health Information Portability and Accountability Act and the Declaration of Helsinki. Considered whether to pursue prospective observational study versus randomized clinical trial are the time and cost associated with the difference in pre-operative 


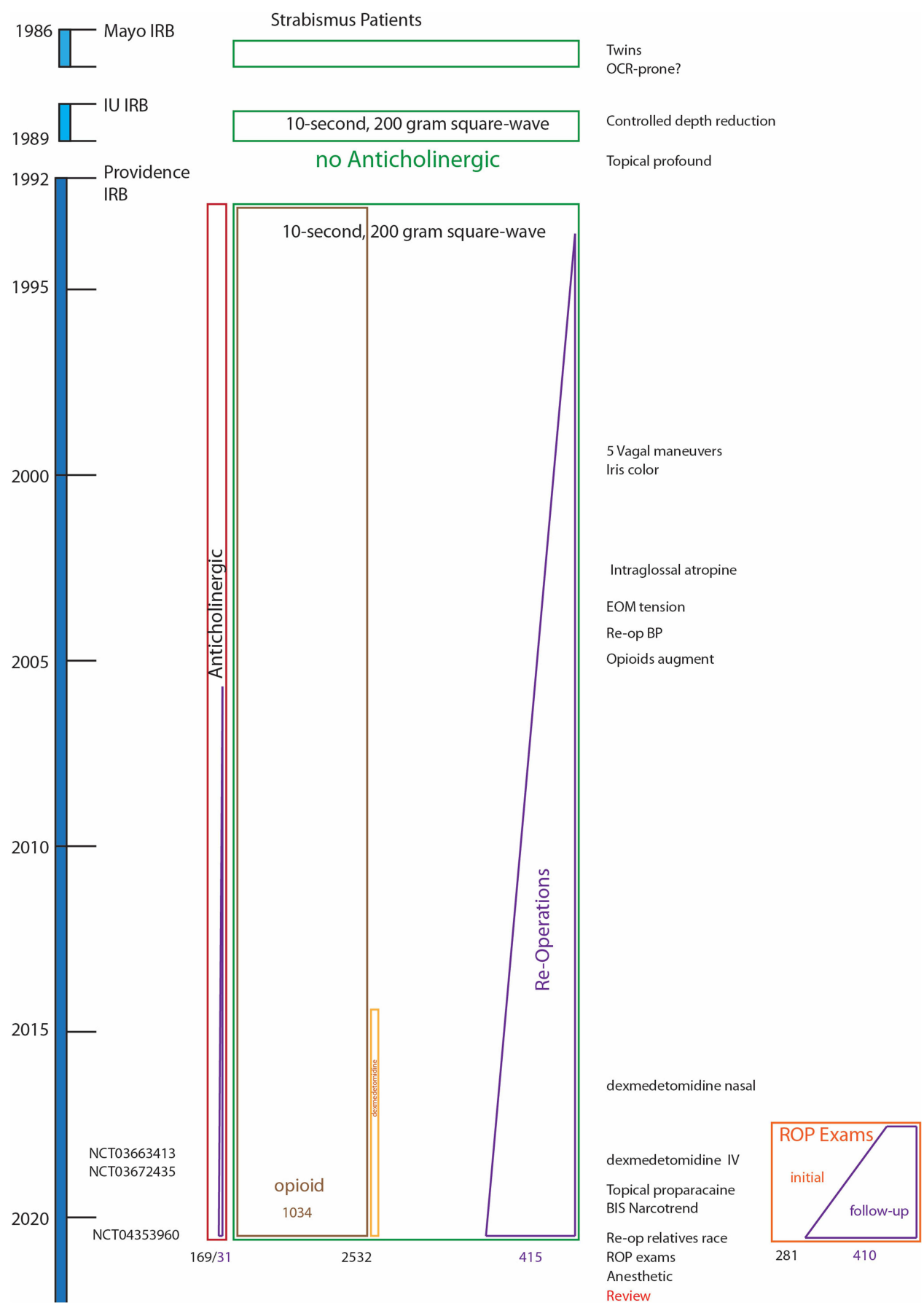

Figure I Timeline for the Alaska OCR Study. Dates on left side including oldest Mayo Clinic and Indiana University (IU) studies. Publications listed to the right side with heart rate response during retinopathy of prematurity (ROP) examinations to lower right. Numbers studied at the bottom.

process with $15 \%$ declining after informed consent. ${ }^{20}$ Additional 15 minutes in pre-operative discussion in day surgery units that would have corresponded to a 2020 corresponding estimated additional \$3.2M (USD) paid by patients for our otherwise unfunded study. De-identified data are available from http://www.abcd-vision.org/OCR/ Ak\%20OCR\%20data\%204-2020.pdf. In each case, OCR was elicited by carefully isolating an extraocular rectus muscle, attaching a custom, sterilizable tension gauge to the Jameson muscle hook, recording stable pre-tension heart rate, and then applying a 10-second, square-wave tension of 200 grams (exactly like EOM surgery) noting the maximal change (bradycardia or tachycardia) in heart rate (Figure 2). Demographic, medical, and anesthetic 
variables were recorded. OCR is reported as the maximally changed heart rate as a percent of stable baseline heart rate.

From 3122 cases, 169 could be separated due to anticholinergic medication, with an additional 5 excluded with orbital block and 1 with a pacemaker. This leaves 2532 original cases without anticholinergic and 446 cases which were re-operations. The original cases were then separated by patient age, by which type of extraocular muscle addressed, and by the opioid used in induction and early maintenance anesthesia. Figure 3 shows the oculocardiac reflex comparing groupings of original cases and those with anticholinergic.

There is a profound influence on OCR by anticholinergic (Mann-Whitney $\mathrm{z}=11.0, \mathrm{P}<0.01$ ), age (Kruskal-Wallis $\left.\mathrm{X}^{2}(2)=85, \mathrm{p}<0.01\right)$, type of extraocular rectus muscle

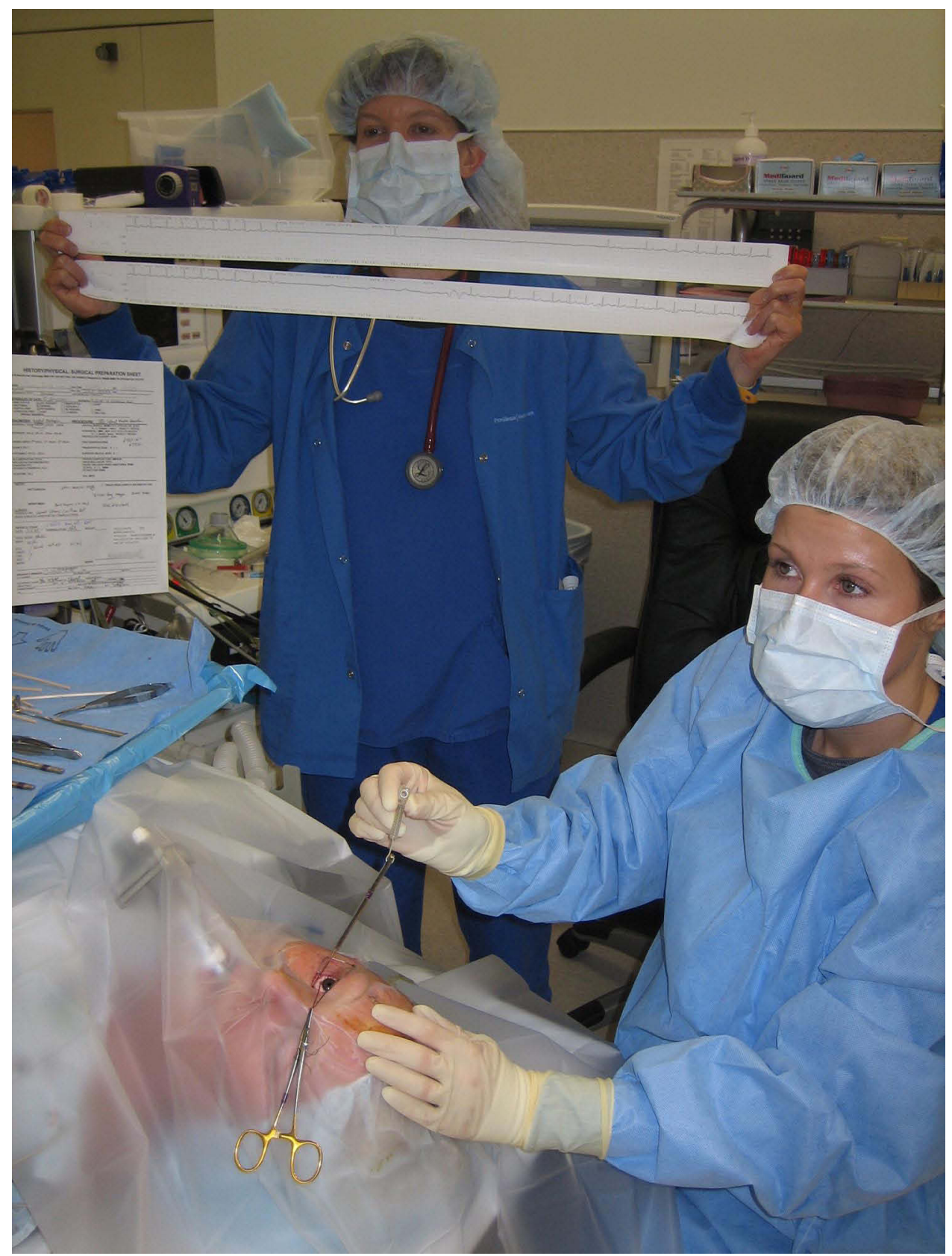

Figure 2 Uniform elicitation of oculocardiac reflex: anesthesiologist records anesthetic parameters and electrocardiograph stable pre-tension heart rate and then maximally altered heart rate as a response to the surgeon's gentle isolation of an extraocular rectus muscle and then utilizing a sterile tension gauge passed through a hole in a Jameson hook and applying a 10 -second, 200 gram square wave tension on the EOM tendon. (The individuals in this image all gave written consent to share for educational purposes). 


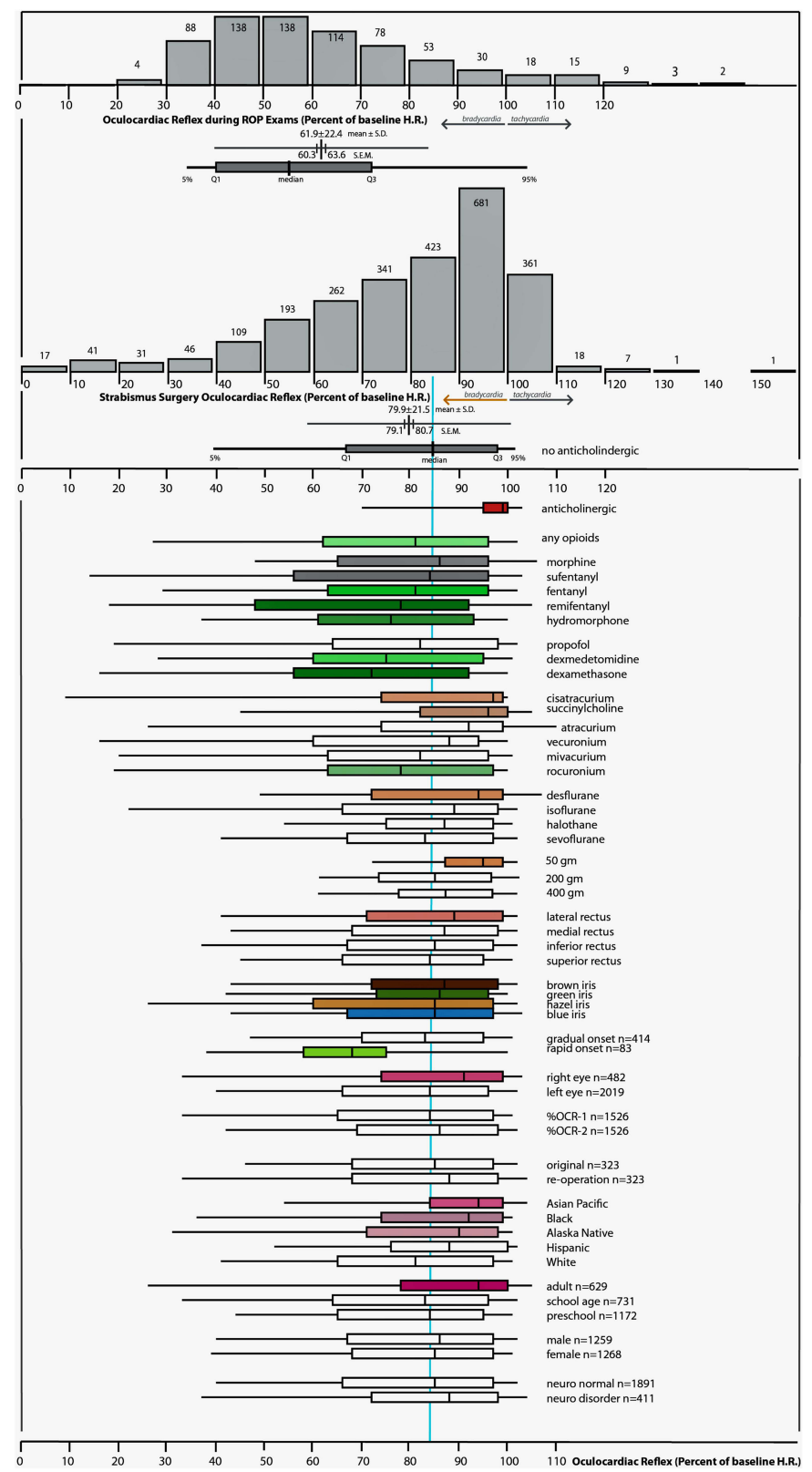

Figure 3 Frequency Distribution; \%OCR is defined as the maximally changed heart rate as a percent of stable baseline heart rate so bradycardia is to the left, tachycardia to the right and $100 \%$ representing no -change. OCR due to retinopathy of prematurity (ROP) exams on top compared with those due to 10-second, 200-gram square wave tension on a gently isolated (rectus) extraocular muscle (EOM) during routine, outpatient strabismus surgery. The median, interquartile range (box) and $95 \%$ limits (whiskers) for various influencers shown below. Green indicates more bradycardia and red indicates less bradycardia.

(Kruskal-Wallis $\left.\mathrm{X}^{2}(3)=8.0, \mathrm{p}<0.05\right)$ and the use of opioid (Kruskal-Wallis $\left.\mathrm{X}^{2}(6)=57.6, \mathrm{p}<0.01\right) .{ }^{21}$ Adults have less OCR than preschool and school-aged children. ${ }^{22}$

\section{Critical Variables}

The Alaska OCR study therefore considers the following variables critical when comparing OCR studies: anticholinergic, age, which EOM, the amount and type of EOM tension and whether opioid was used.

\section{Sample Size}

A wide inter-case variability in OCR is noted with a range from $5 \%$ (profound bradycardia) to $151 \%$ (tachycardia) and a mean of $79.9 \pm 20 \%$. The frequency distribution for OCR is not normal; most patients have relatively small change in heart rate. The sample size to detect a 3\% difference between two groups with mean $80 \%$ and standard deviation $20 \%$ with alpha 0.05 and power 0.8 is about 700. In a 2007 report, the authors of an otherwise carefully 
designed randomized trial explained the lack of sample size calculations thus: "We chose the group size of 15 in each group without conducting a power analysis as there were no previous comparable studies." ${ }^{23}$ Very few of $200+$ prior OCR studies have sufficient sample size to detect moderate to small difference in effect. ${ }^{24}$ The largest comparison group in randomized controlled trials (RCT) of OCR is $100 .{ }^{25}$ With OCR as secondary analysis, a recent RCT selected sample size of 28 per group to detect a $40 \%$ difference in effect not on OCR but rather on emergence agitation. ${ }^{20}$ Prior underpowered studies have been referenced as the reason for following their example striving for only about 30 per group. ${ }^{26}$

\section{Method of Literature Search}

English and non-English reviews, case reports and clinical studies as well as related trigeminovagal reflexes and veterinary cases were sought. Online databases MEDLINE, PUBMED, National Library of Medicine were searched up through April 2021 using the following terms, "oculocardiac," "trigeminovagal," "diving response," "globe pressure," and "oculorespiratory reflex." In addition to sample size, each paper was entered into an EndNote library and an Excel database and critically assessed relative to definition of OCR, which $\operatorname{EOM}(\mathrm{s})$ were tested and quantity of tension, patient age and the presence of anticholinergic and opioid medications.

Neuroanatomy of the Oculocardiac Reflex: The oculocardiac reflex is perhaps the most famous of a group called the trigeminovagal ${ }^{27}$ reflexes (Figure 4). Various stimuli around the orbit can trigger including pain and pressure, however the classic form of oculocardiac reflex is elicited by extraocular muscle tension mediated through stretch or proprioceptors. ${ }^{28}$ The afferent arc travels through ciliary nerves as part of the first division of the trigeminal nerve through the Gasserian ganglion to the trigeminal sensory nucleus. Then, for reasons for which I have no teleological explanation, an immediate impulse is transmitted through the visceral motor nucleus of the vagus nerve resulting in various degrees of cardiac slowing, and bradydysrhythmias such as loss of p-waves and premature ventricular beats. A different trigemino-vagal reflex is the diving reflex, ${ }^{29}$ initiated best by apneic, cold facial immersion that results in profound peripheral vasoconstriction followed by a substantial bradycardia. The diving reflex helps keep diving animals alive and is less consistently demonstrated in humans. It has not been clear whether the oculocardiac reflex shares the peripheral vasoconstriction and maintained central blood pressure with its trigeminovagal "cousin," the diving response.

\section{Influence of Anesthesiologist}

The anesthesiologist has a profound influence on OCR with ability to reduce or prevent bradycardia with anticholinergic medications if a sufficient dose is delivered in advance of ocular manipulation. ${ }^{21}$ Certain anesthetics can also potentiate OCR.

\section{Monitoring \\ ECG}

Most studies on OCR utilize electrocardiograph (ECG) monitoring ${ }^{30}$ particularly using the tachometer of a cardiac monitor. ${ }^{31}$ A pulse oximeter has been used. ${ }^{32}$ The automated heart rate function of various monitors utilizes the average of different numbers of R-R intervals such that the actual lowest heart rate representing the longest R-R interval may be more accurately extracted from an actual ECG print out than the ongoing average heart rate. Other monitors report "asystole" when the R-R interval extends longer than a pre-determined duration. A Holter monitor was used to find $43 \%$ with bradycardia following strabismus surgery. ${ }^{33}$

\section{Criteria for Defining OCR}

Some authors define OCR as any ECG change ${ }^{18,34,35}$ or, like the Alaska OCR study, report each case as a percent change in heart rate. ${ }^{22,36-39}$ For a patient with pre-tension heart rate of $120 \mathrm{bpm}$ dropping to $80 \mathrm{bpm}$ with EOM tension, the percent change in heart rate has been reported as the amount of drop $(-33 \%)$ or the OCR heart rate as a percent of pre-heart rate ${ }^{21,22}$ $(66 \%)$. The reciprocal of the percent heart rate is related to prolongation of the R-R interval. ${ }^{40,41}$ Some authors count cases with heart rate drop below $60 \mathrm{bpm} .{ }^{42,43}$ Yi et al reported the average lowest heart rate during EOM traction. ${ }^{44}$ Others define OCR as a drop of a fixed number of beats per minute (bpm) whether in children or adults expressed as greater than 7 bpm, ${ }^{45,46} 10$ b.p.m., ${ }^{30,47-50} 12$ bpm, ${ }^{51}$ or 20 b.p.m. ${ }^{52,53}$ Other authors facilitate comparison between children and adults by using percent heart rate change: a decrease of $10 \%,{ }^{32,54-64}$ a decrease of $15 \%,{ }^{43,65-69}$ a decrease of $20 \%$. $^{5,20,23,24,39,70-85}$ Figure 5 shows the frequency distribution and cumulative prevalence of \%OCR for the Alaska OCR project compared to cases defined as more than $10 \%$ or $20 \%$ heart rate drop. Profound OCR can be defined as greater than $33 \%{ }^{86}$ or a $50 \%$ decrease in heart rate. ${ }^{22}$ Rahimi Varposhti et al go further by defining "mild" OCR as 20\%-30\% HR drop, "moderate" OCR 


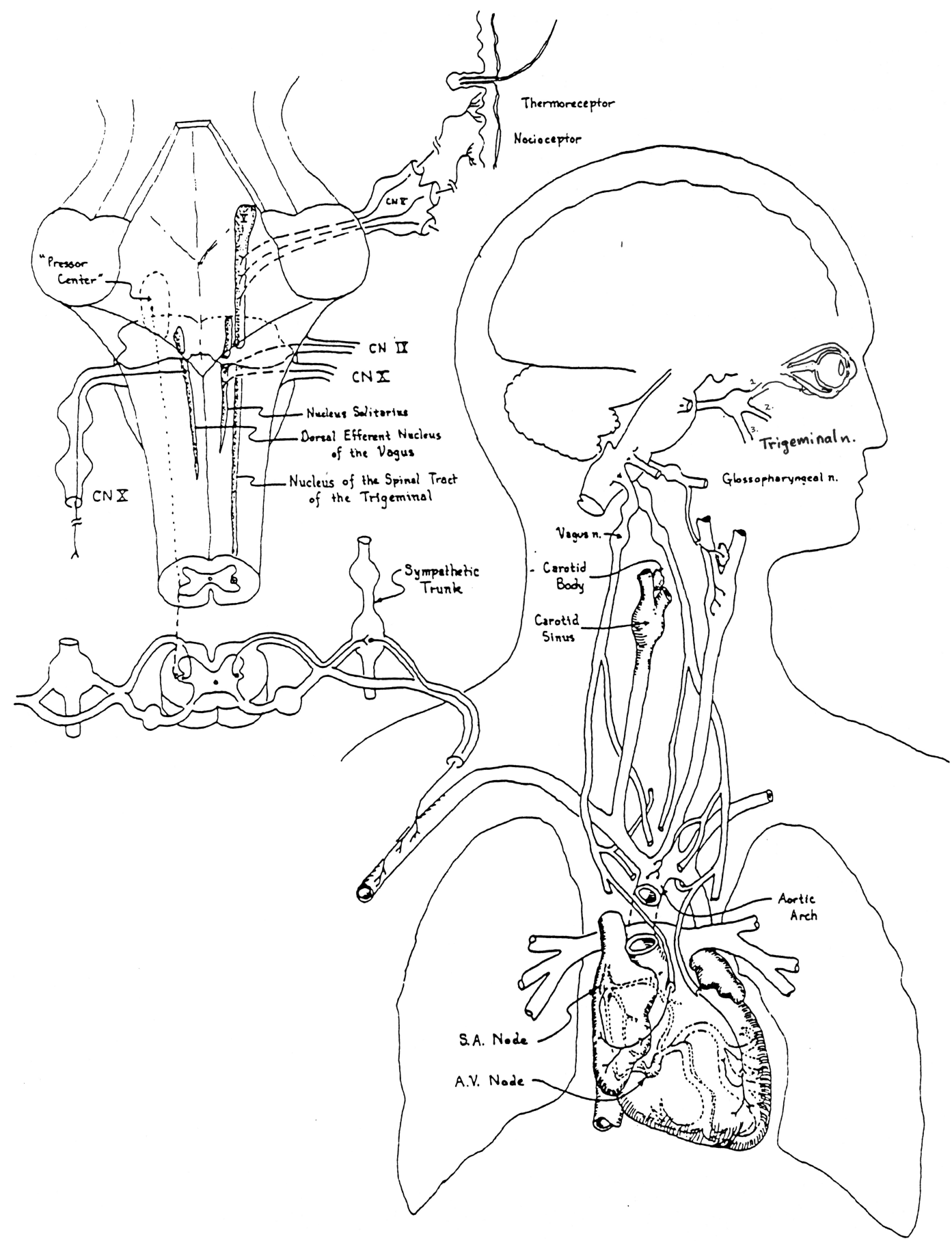

Figure 4 Neuroanatomy of the oculocardiac reflex. Trigeminal nerve afferents including extraocular muscle proprioceptors travel from the first division of the trigeminal nerve to be processed in the brain stem with efferent the cardiac vagus nerve.

Notes: Figure by RW Arnold. Adaptedfrom the Journal of the American Academy of Ophthalmology. Arnold RW, Gould AB, McKenzie R, Dyer JA, Low (P) Lack of global vagal propensity in patients with oculocardiac reflex. 1994;10I (8): 1347-1352. ${ }^{128}$ Copyright $\odot 1994$ American Academy of Ophthalmology, Inc. Published by Elsevier Inc. All rights reserved, with permission from Elsevier.

as $30 \%$ to $40 \%$ drop and "severe" as greater than $40 \%$ heart rate drop. ${ }^{87}$ Mizrak reported the percent who did not have $20 \%$ heart rate decrease. ${ }^{88}$ Snellen's OCR criteria was less than $20 \%$ of pre-induction $\mathrm{HR}^{89}$ Recognizing that OCR is not normally distributed, non-parametric statistics (medians) should be reported. ${ }^{90}$ Tramér et al reported the numberneeded-to-harm in randomized clinical trials. ${ }^{77,91} \mathrm{Kim}$ et al used Neural Networks in 16 patients attempting to predict OCR. ${ }^{92}$ Some studies combine bradycardia with other ectopic arrhythmias. $^{20,23}$ Mehmood and Hasan describe OCR from 

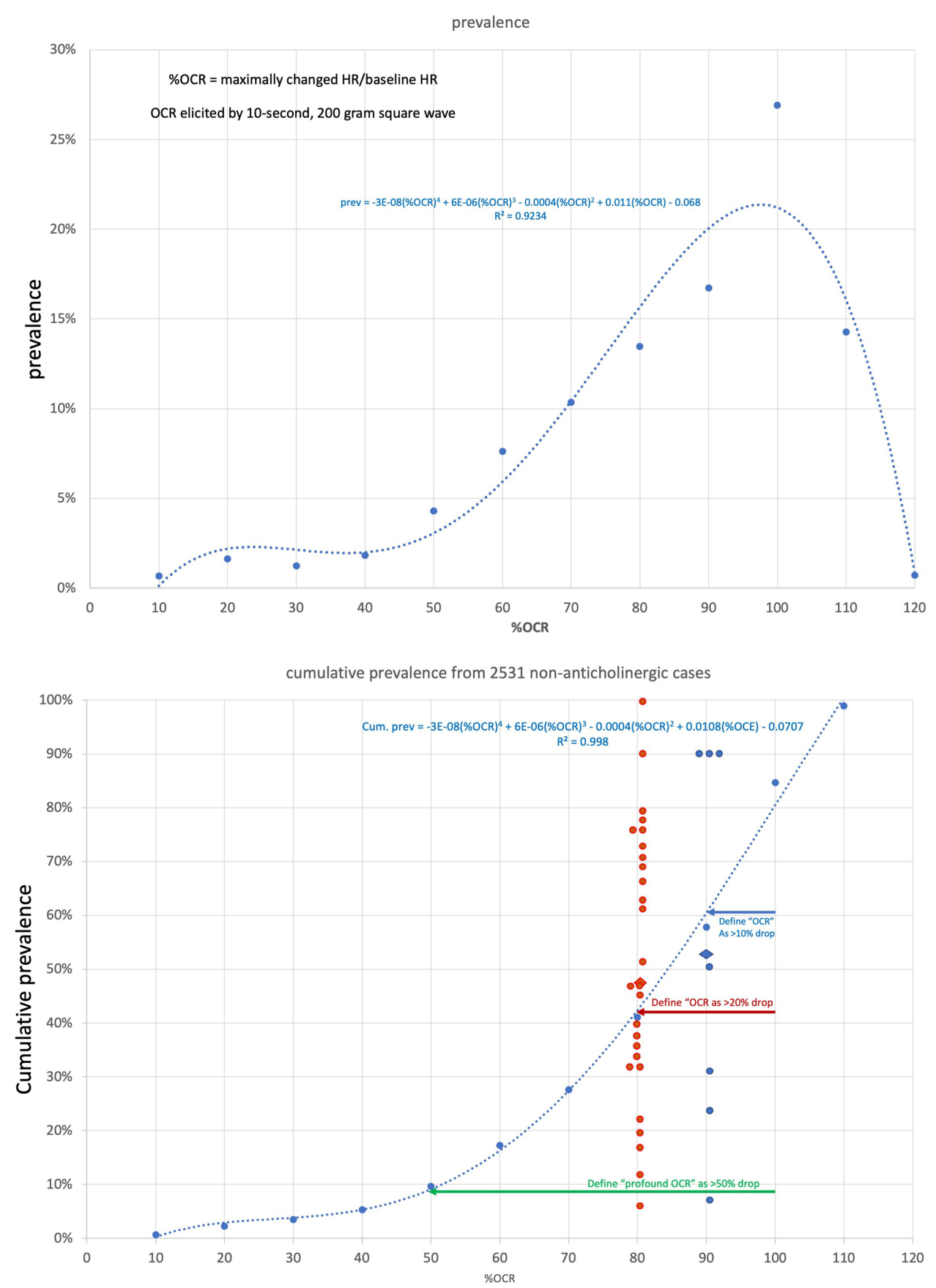

Figure 5 Cumulative Prevalence and past proportions. Curve fit for prevalence of \%OCR versus degree of OCR (top) for adults and children undergoing 10 -second, 200 gram square wave tension on rectus extraocular muscle (EOM). Bottom shows the compared cumulative prevalence including published studies that report OCR defined as $10 \%$ or more OCR (blue arrow), $20 \%$ or more OCR (red arrow) and profound $50 \%$ or more heart rate drop (green arrow).

orbital fracture as a triad of "bradycardia, syncope and nausea." 93

The common criteria by which OCR has been defined are compared to the prevalence distribution for \%OCR determined by the uniform 10-second, 200 gram EOM rectus tension in the Alaska OCR study (Figure 3). The prevalence by $10 \%$ bins for $\% \mathrm{OCR}$ prevalence when OCR is defined as the maximally changed heart rate as a percent of stable pre-tension heart rate is: prevalence $=-3 \mathrm{E}-08(\%$ $\mathrm{OCR})^{4}+6 \mathrm{E}-06(\% \mathrm{OCR})^{3}-0.0004(\% \mathrm{OCR})^{2}+0.0105(\%$ OCR) - 0.0683 (Figure 5). When OCR without anticholinergic is defined as more than $10 \%$ heart rate drop $\mathrm{AK}$ OCR found $58 \%$, when OCR is defined as more than $20 \%$ heart rate drop AK OCR found $41 \%$, and when OCR 
profound is defined as more than $50 \%$ heart rate drop, AK OCR found $10 \%$ of patients had that much bradycardia.

\section{Extremes in Bradycardia}

The low heart rate reported by various studies of OCR has been $43 \mathrm{bpm},{ }^{30} 35 \mathrm{bpm},{ }^{60} 30 \mathrm{bpm},{ }^{55} 25 \mathrm{bpm},{ }^{54} 20$ b.p. $\mathrm{m},{ }^{75,94} 17 \mathrm{bpm},{ }^{72} 16 \mathrm{bpm},{ }^{95} 13 \mathrm{bpm},{ }^{46} 12 \mathrm{bpm},{ }^{96} 10$ bpm, ${ }^{50} 6$ b.p. $\mathrm{m}^{97}$ and 3.8 b.p.m. ${ }^{48}$ Heart rate can drop to $5 \%$ of stable pretension heart rate at one end of the spectrum of OCR while others may have tachycardia to $151 \%$ of pretension heart rate. ${ }^{22}$ Two of 822 ophthalmic cases done under general anesthesia had "cardiac arrest" requiring resuscitation. ${ }^{98}$ In adult humans, the inherent rate of the sinoatrial node is about $72 \mathrm{bpm}$, the atrioventricular node $45 \mathrm{bpm}$ and the ventricular tissue $30 \mathrm{bpm}$. Several cases of oculocardiac reflex result in vagal suppression of cardiac automaticity to below inherent rhythm. Extremes of OCR in the Alaska OCR study are shown in Figure 6.

\section{Onset}

Gradual versus rapid: Ohashi et al noted a latency from traction 50-600 grams of 1.0 to 2.5 seconds to development of OCR. ${ }^{37}$ The oculocardiac reflex has a prompt onset compared to other vagal reflexes Valsalva maneuver and particularly diving response. ${ }^{99}$ Patients with rapid onset OCR defined as more than $25 \%$ change in first two seconds had percent OCR $18 \%$ more than gradual onset cases. $^{100}$

\section{Vagal Dysrhythmias}

Alexander found $5 \%$ of OCR with ectopic rhythms. ${ }^{101}$ Munden noted dysrhythmias during optic nerve crush in 3 enucleations. ${ }^{102}$ Compared to $31.8 \%$ with vagal bradycardia, 5.7\% had other rhythm disturbances. ${ }^{42}$ Grover in retina patients found $20 \%$ with vagal dysrhythmias with nitrousnarcotic general anesthesia but only $7 \%$ with peribulbar block. ${ }^{50}$ Junctional rhythm accompanied prolonged bradycardia with trap-door orbital fractures. ${ }^{103}$ Atrioventricular rhythm disorders were more common in 10 patients with propofol compared to ketamine.$^{64}$ Persistent A-V block can accompany zygomatic fracture. ${ }^{104}$ In a randomized trial of muscle relaxants and OCR, A-V nodal rhythm and premature ventricular contractions (PVC) were $6 \%$ with rocuronium, $22 \%$ with succinyl choline and $19 \%$ with none. ${ }^{67}$ One of 45 strabismic children had "asystole" while 2 had ventricular ectopic beats. ${ }^{23}$ Lai et al found 3 of 111 strabismus patients had dysrhythmias. ${ }^{105}$

\section{Tachycardia}

Pöntinen, in one of the largest OCR studies using neuroleptanalgesia, ${ }^{48}$ noted some tachycardia and described "positive" and "negative" OCR. ${ }^{48}$ Fessl-Alemany treated "paradoxical OCR" with pindolol. ${ }^{106}$ Compared to other vagal maneuvers including globe pressure which were devoid of tachycardia, uniformly elicited surgical OCR shows tachycardia in up to $10 \%$ of patients even without anticholinergic. ${ }^{107}$

\section{Oximetry}

OCR has been monitored with pulse oximetry that lacks a recorded tracing. ${ }^{97}$

\section{Blood Pressure}

Anderson noted that the blood pressure dropped during bradycardia induced by eyelid surgery. ${ }^{108}$ Rabbit EOM tension produces hypotension reversed by retrobulbar block but not by anticholinergic. ${ }^{109}$ Accompanying prolonged bradycardia in 3 orbital fracture patients was moderate hypotension that resolved after fracture repair. ${ }^{103}$ Hahnenkamp et al measured BP during 90-second, 400-600 gram EOM tension finding hypertensive $10 \mathrm{mmHg}$ increase with ketamine but BP drop of $3 \mathrm{mmHg}, 5 \mathrm{mmHg}$ and $8 \mathrm{mmHg}$, respectively, for sevoflurane, halothane and propofol-alfentanil. ${ }^{64}$ Real-time arterial blood pressure (Figure 6) was not maintained by concomitant peripheral vasoconstriction during OCR in an OCR-prone patient. ${ }^{110}$

\section{Oculo Respiratory Reflex (ORR)}

During strabismus muscle traction in spontaneously ventilating patients, the respiratory drive may decrease. ${ }^{111}$ Shin et al defined and ORR as a $20 \%$ reduction in respiratory variables during strabismus EOM manipulation noting more ORR based on tidal volume, particularly in children and more with medial rectus than lateral rectus (multiple comparisons). ${ }^{5}$

\section{Other}

Electroencephalography (EEG) and bispectral index (BIS) has been used to observe OCR ${ }^{55,56,100}$ Morel et al maintained intravenous general anesthesia with BIS monitor 40-50. ${ }^{112}$ OCR has also been studied with arterial oscillography. ${ }^{113}$ Arterial blood gases were normal during OCR. ${ }^{45,55}$ Adductor pollicis evoked potential was monitored during OCR with various muscle relaxants, ${ }^{73} \mathrm{~A}$ Cardiorater was used in addition to ECG. ${ }^{49}$ Serum gastrin concentrations were not different in 5 out of 10 strabismic children who had OCR or in those with PONV. ${ }^{51}$ 
Profound Oculocardiac Reflex electrocardiographs and arterial pressure from the Alaska Oculocardiac Reflex Study

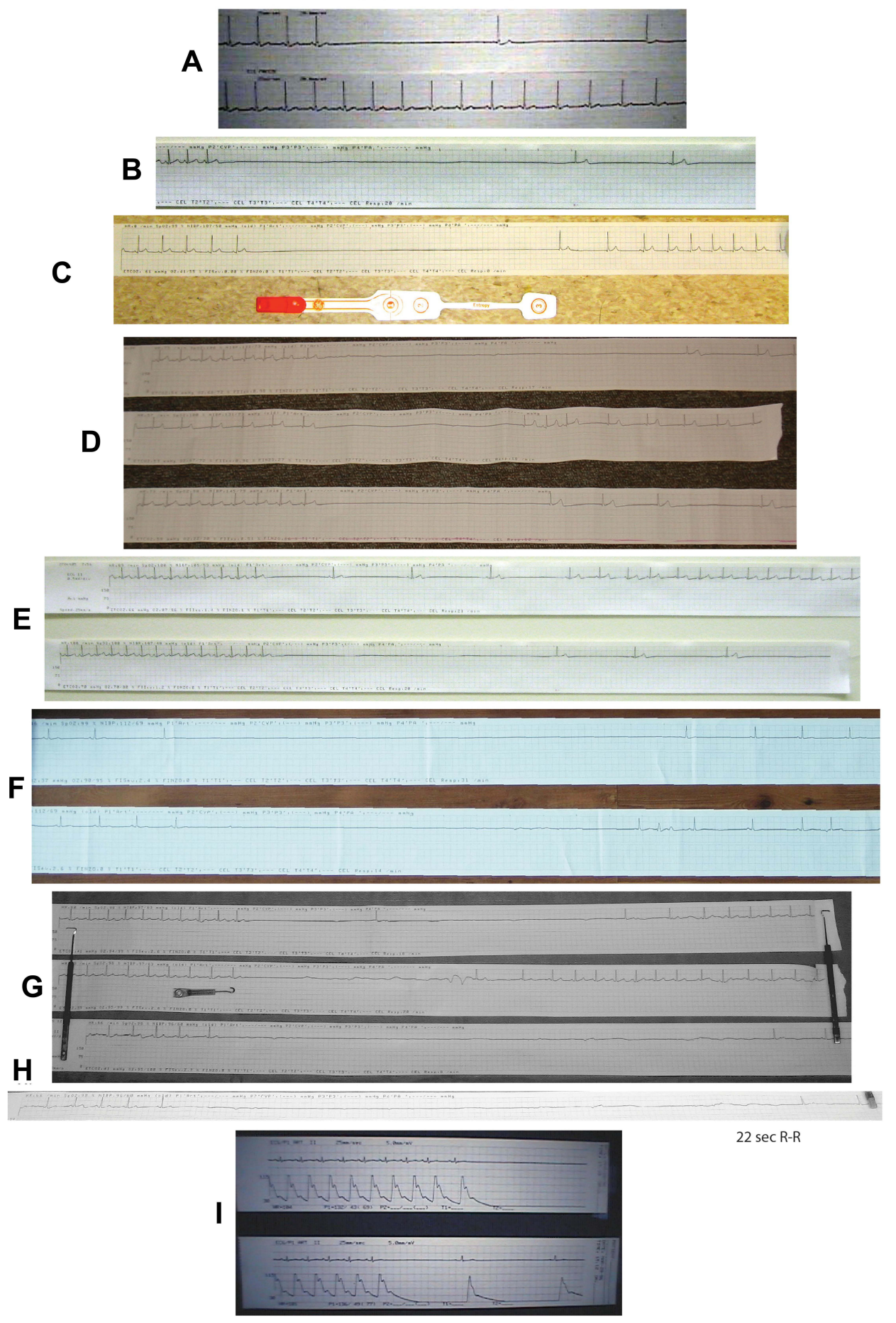

Figure 6 Extremes in oculocardiac reflex. From the Alaska OCR study: (A) influence of I.V. push remifentanil versus none. (B) Profound OCR. (C) Narcotrend brainwave monitor and profound OCR. (D, E and F) Multiple EOM tension during each case. (G) OCR with 20 second R-R interval repeat with jameson muscle hooks and OCR tension gauge. (H) OCR with healthy adult athletic baseline heart rate rapidly showing 22 second R-R interval elicited by 10 -second, 200 gram square wave tension on the inferior rectus muscle. (I) Oculocardiac reflex electrocardiograph and arterial pressure.

\section{Anesthetic Agents Anticholinergic}

Some authors found retrobulbar block better than anticholinergic to reduce $\mathrm{OCR},{ }^{34,56}$ but others thought anticholinergic better than orbital block. ${ }^{55}$ Intramuscular scopolamine $^{47}$ and subcutaneous atropine ${ }^{35}$ were not sufficient to block OCR. Taylor et al found $28 \%$ OCR with IV atropine, 58\% OCR with none and $0 \%$ OCR with 
retrobulbar block in children undergoing strabismus surgery. ${ }^{52}$ IV glycopyrrolate blocked more than mechanical ventilation in strabismus patients. ${ }^{72}$ Alexander found 25\% OCR with IV atropine, 70\% OCR with pre-op IM atropine and 90\% OCR with no anticholinergic. ${ }^{101}$ With recent ( $<20$ minutes) IV hyoscine $10-20 \mathrm{mg}$, OCR was reduced at least for the first EOM in strabismus cases. ${ }^{114}$ Hunsley in 80 children $^{58}$ and Mirakhur in 160 children $^{70}$ compared atropine to glycopyrrolate in strabismus surgery; OCR reduction was dose dependent. Karhunen in another dose response OCR study felt glycopyrrolate was twice as potent as atropine. ${ }^{71}$ Intramuscular atropine reduced OCR from $77 \%$ to $20 \%{ }^{76}$ Atropine IV plus lidocaine blocked OCR best with ether anesthesia. ${ }^{115}$ With prolonged, high tension on EOM, atropine blocked vagal influence but uncovered tachycardia. $^{90}$ Atropine IV produced $18 \%$ OCR vs $60 \%$ without. ${ }^{65}$ With uniform EOM tension stimulating the OCR, atropine by IV route $(-2.3 \%)$ and intraglossal $(-0.9 \%)$ had a greater preventative impact on OCR than oral $(-6.7 \%)$ and intra-deltoid $(-6.8 \%)$ route compared to $-17.2 \%$ with no anticholinergic. ${ }^{38}$ Intravenous atropine before strabismus cases reduced OCR from $70 \%$ to $10 \%$ and severe OCR from $40 \%$ to $0 \%$. ${ }^{116}$ Aletaha et al avoided atropine finding the incidence of OCR defined as a $15 \%$ HR drop to be $86 \%$ of their patients. $^{68}$ With uniformly elicited OCR defined as the percent of stable pre-tension heart rate, 165 initial cases with intravenous anticholinergic (atropine and glycopyrrolate) had much reduced OCR $(99 \%$, CI 70\%, 103\%) compared to 2527 initial, age-matched non-anticholinergic cases $(85 \%$, CI $39 \%, 102 \%){ }^{21}$ The Alaska OCR study prioritizes cases without anticholinergic if determined safe by the anesthesiologist. ${ }^{117}$

\section{Muscle Relaxants}

Alcuronium protected against OCR more than tubocurare, pancuronium and vecuronium after pre-op IM atropine with only 20 patients in each group. ${ }^{73}$ Gallamine protected against OCR more than tubocurare. ${ }^{54}$ Loewinger in a randomized trial lacking muscle tension quantification found atracurium produced 90\% OCR compared to pancuronium $60 \%{ }^{75}$ Karanovic found OCR $29 \%$ with rocuronium, 53\% with succinyl choline and $44 \%$ with none. ${ }^{67}$ Karanovic again found $27 \%$ OCR with rocuronium and $47 \%$ with none during medial rectus surgery in Croatian children. ${ }^{118}$ Uniformly elicited OCR expressed as percent of stable pre-tension heart rate was least with cisatracurium 97\%, then succinyl choline 96\%, then atracurium 92\%, then vecuronium $88 \%$, then mivacurium $82 \%$ and most OCR for muscle relaxant rocuronium $78 \% .^{21}$ In a recent retrospective logistic regression analysis of strabismus surgery in children, the 37 who received rocuronium were 3.1 times less likely to have $20 \%$ OCR than the 49 who did not get neuromuscular blockade. ${ }^{85}$

\section{Inhalational Agent}

OCR has been studied with ether and nitrous oxide. ${ }^{55}$ Reed used cyclopropane, ether and nitrous oxide. ${ }^{56}$ Misurya used ether. ${ }^{115}$ Allison et al found sevoflurane produced less OCR ( $38 \%$ of events, $-17 \% \mathrm{HR})$ than similar 1.3 MAC halothane (79\% events, $-28 \% \mathrm{HR})$ in a randomized trial in children. ${ }^{78}$ Sevoflurane had $14 \%$ incidence of OCR compared to $75 \%$ with propofol in a larger randomized clinical trial in children with strabismus. ${ }^{79}$ The median uniformly elicited OCR as percent of stable pre-tension heart rate for sevoflurane was most with $84 \%$, then halothane $87 \%$, then isoflurane $89 \%$ and least OCR with desflurane $94 \%$. $^{21}$

\section{Anesthetic Depth}

Deeper anesthesia was thought to reduce OCR. ${ }^{30}$ Compared to historic controls, monitored deep inhalational anesthesia with halothane or isoflurane and robust ventilation produced a low average percent OCR of $8 \pm 9 \%$ even without anticholinergic. ${ }^{19} \mathrm{Yi}$ et al randomized the concentration of sevoflurane to target levels of BIS finding less OCR (32\%) with BIS-50 and BIS-40 (11\%) than with BIS $60(71 \%)$ and the lowest average HR was less with BIS 60 $(112 \pm 18 \mathrm{bpm})$ than with BIS $40(121 \pm 16 \mathrm{bpm}) .{ }^{44}$ Slight anesthesia had more trigeminovagal reflex by "Cerebral State Index" than deeper anesthesia. ${ }^{119}$ Karaman et al randomized the regulation of desflurane concentration directed by BIS 40-49 compared to BIS 50-59 showing deeper anesthesia had less $20 \%$ OCR (25\% to 64\%) compared to lighter inhalational anesthesia. ${ }^{81}$ Using uniformly controlled EOM tension and intra-subject controls, variations in volatile anesthetic depth assessed by BIS and Narcotrend EEG monitors failed to show modifying impact on OCR. ${ }^{100}$ Deeper volatile anesthetics protected against OCR for halothane, isoflurane and sevoflurane (Figure 7), and intra-patient compared OCR correlated with the difference in expired agent for halothane, isoflurane and sevoflurane with only desflurane having minimal impact on OCR. ${ }^{21}$ 


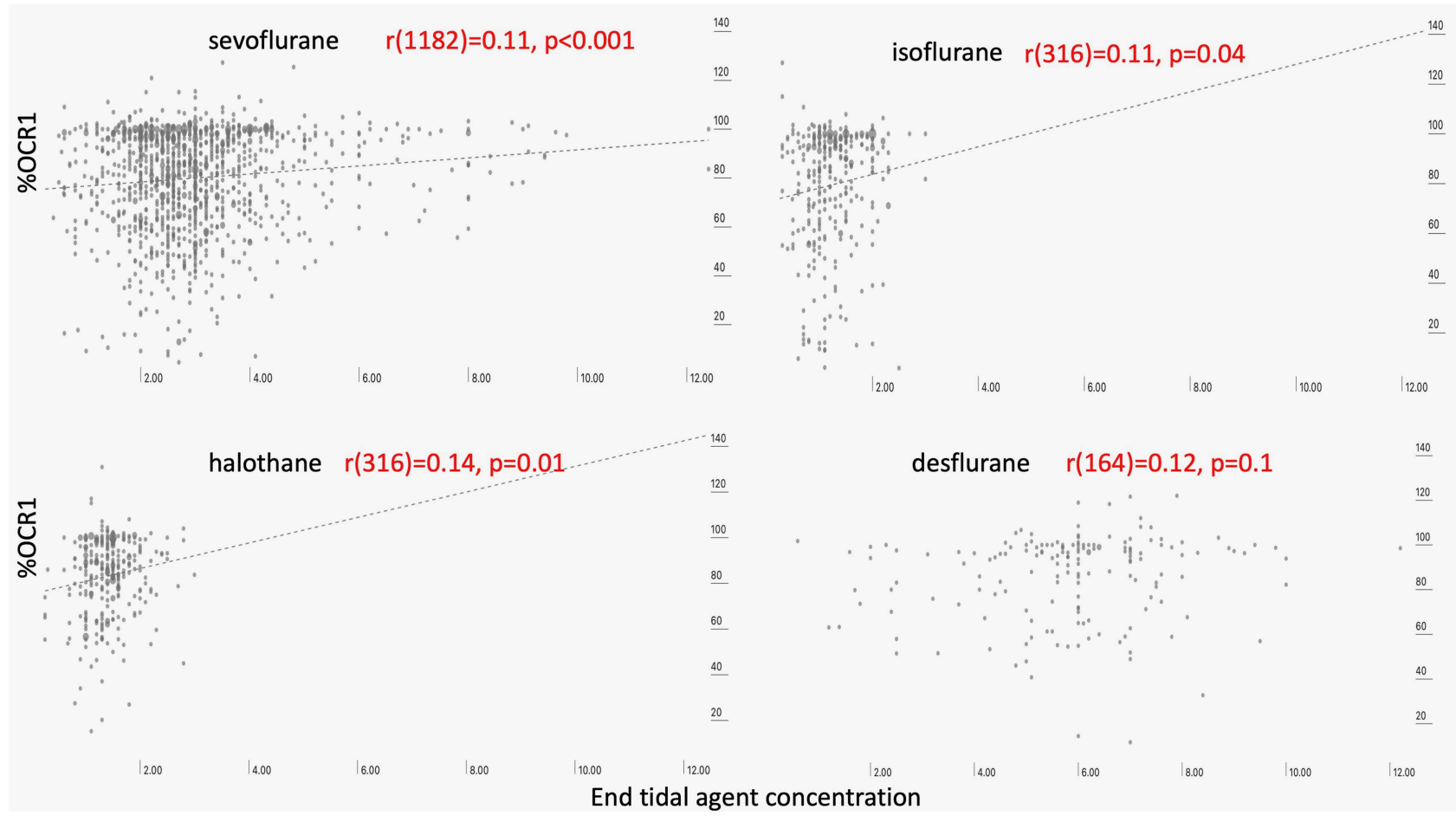

Figure 7 Influence of agent concentration (depth of anesthesia). The \%OCR correlated with end-tidal concentration of inhaled anesthetic agent showing significantly less \% OCR for deeper levels of agent for sevoflurane, halothane and isoflurane, but insufficient numbers of desflurane patients.

$\mathrm{N} 2 \mathrm{O}$

There was minimal impact on OCR based on presence and percentage of nitrous oxide mixed with oxygen in volatile anesthesia. $^{21}$

\section{$\mathrm{CO} 2$}

Ventilated patients had more OCR than spontaneously breathing. ${ }^{72}$ Moonie found that OCR occurs even with normal $\mathrm{CO} 2$ levels. ${ }^{94}$ Alexander found $\mathrm{CO} 2$ in the range of $46-73 \mathrm{mmHg}$ in cases with OCR. ${ }^{101}$ Forestner and Imbrecht found a similar rate of OCR with spontaneous ventilation or strictly maintained $\mathrm{CO} 2$ of $35-38 \mathrm{mmHg} .{ }^{120}$ Hypercarbia produced more OCR when expired $\mathrm{CO} 2$ was correlated (Figure 8, $\mathrm{p}<0.01$ ) and the difference in OCR correlated with difference in $\mathrm{CO} 2$ for intra-patient controlled correlation. $^{21}$

\section{Airway}

Allison and Steibet al were early adopters of laryngeal mask airway (LMA) ${ }^{78,121}$ Liu et al compared total intravenous anesthesia (TIVA) without airway to sevofluranenitrous with LMA finding less OCR in the volatile group. $^{122}$

\section{Opioids}

Pöntinen used fentanyl with neuroleptanalgesia after intramuscular atropine and got one OCR slowing to 3.8 b.p.m. with "deliberate" EOM tension. ${ }^{48}$ Morphine was associated with less OCR during retinal detachment surgery. ${ }^{123}$ Queinnec et al used dextromoramide in both arms of their randomized trial. ${ }^{74}$ Sufentanil in 1990 was suspected to augment OCR. ${ }^{124}$ Uniformly elicited OCR (without opioid $-17 \pm 18 \%)$ was augmented by induction remifentanil $(-50$ $\pm 36 \%$ ), sufentanyl $(-26 \pm 29 \%)$, and fentanyl $(-24 \pm 24 \%)$ but unchanged with morphine $(-15 \pm 16 \%) .{ }^{117}$ Intra-subject comparison with first EOM $-20 \pm 18 \%$ was augmented in the second EOM $(-28 \pm 19 \%)$ when fentanyl was given in between but unchanged with meperidine in between first and second EOM. ${ }^{117}$ Chung et al in an RCT found opioid augmented OCR $58 \%$ vs $28 \%$ and a drop of $-23 \pm 17 \%$ versus $-11 \pm 13 \%$ when remifentanil was compared to none in 120 children. ${ }^{39}$ Zhu et al found $44 \%$ OCR with remifentanil-propofol maintenance versus $17 \%$ with desflurane. ${ }^{83}$ Induction fentanyl $(-27 \pm 7 \%)$ had more augmenting impact on OCR than none $(-19 \pm 4 \%) .{ }^{125}$ Opioids except morphine potentiated $\mathrm{OCR}^{21,22}$ with median OCR as percent of stable pre-heart rate with hydromorphone most with $76 \%$, then remifentanil $78 \%$, then fentanyl $81 \%$, then sufentanyl $84 \%$ and least with morphine $86 \%{ }^{21}$ 


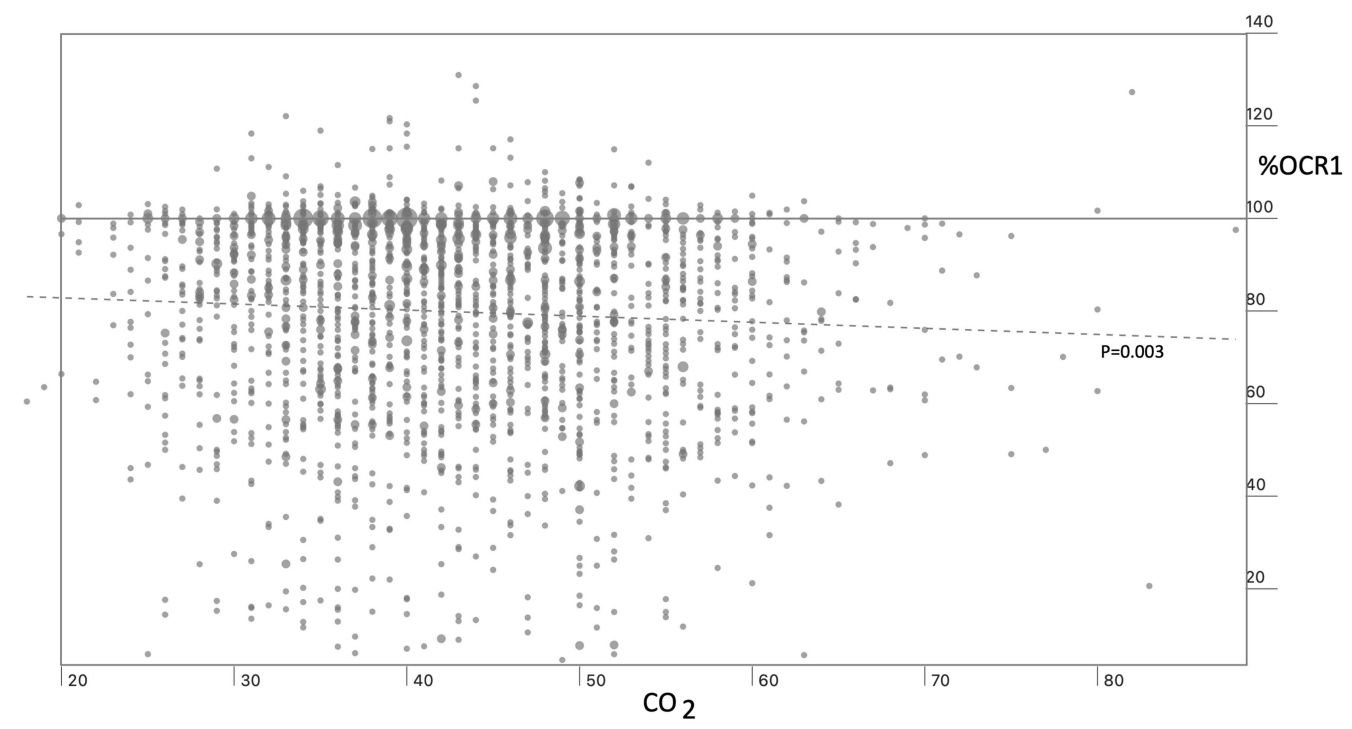

Figure 8 Influence of $\mathrm{CO} 2$ concentration. There is a trend toward more bradycardia due to OCR with hypercarbia.

\section{Sedatives}

Apivor and Ravi used ketamine with or without atropine in 50 strabismus cases. ${ }^{36}$ Hahnenkamp et al in a small randomized trial found OCR with ketamine $22 \%$ while propofolalfentanil, sevoflurane-nitrous and halothane nitrous all had $90 \%$ OCR elicited by 90 second, 500 gram pull. ${ }^{64}$ Thiopental for strabismus surgery was used extensively early ${ }^{35,54-56,58,70,71,94,97,126}$ and recently. ${ }^{19,62,127,128}$ Dexmedetomidine randomly added to IV ketamine in a small, non-tension-controlled study of strabismic children produced $30 \%$ OCR compared to placebo with $77 \%{ }^{88}$ Song et al randomized 4 groups with slow infusion concentrations of dexmedetomidine showing identical $-36 \%$ impact on OCR. ${ }^{20} \mathrm{Li}$ et al randomized slow infusion dexmedetomidine showing less OCR with non-quantified EOM tension than with placebo. ${ }^{84} \mathrm{Oh}$ et al in a small randomized trial found that induction ketamine sufficient to increase resting blood pressure did not increase OCR (10\%) compared to induction midazolam (19\%). ${ }^{80}$ Espahbodi et al in an RCT found OCR $20 \%$ with ketamine induction versus $43 \%$ with induction atropine and $63 \%$ with no induction drugs. ${ }^{129}$

\section{Propofol}

Queinnec et al compared propofol maintenance to enflurane in children. ${ }^{74}$ Wachta in a randomized trial of postoperative nausea and vomiting (PONV) in children found $55 \%$ OCR with propofol maintenance to be more than the $30 \%$ with halothane + droperidol but the propofol had less (23\% compared to $50 \%$ ) PONV. ${ }^{66}$ Slow injected induction propofol with vecuronium and less fentanyl had less OCR and PONV than fast infusion propofol with more fentanyl. ${ }^{130}$ Propofol-remifentanil maintenance had more OCR than desflurane in adult strabismus cases. ${ }^{83}$ Propofolnitrous oxide produced $50 \%$ OCR compared to thiopentalisoflurane-nitrous oxide $15 \%$ and with less PONV with propofol. ${ }^{89}$ Tramer et al in a randomized clinical trial in children compared propofol to thiopentone-isoflurane finding OCR $40 \%$ compared to $14 \%$ with similar PONV for both. ${ }^{91}$ Propofol as induction or maintenance anesthesia when opioids and anticholinergics controlled had minimal impact on OCR (87\% compared to $85 \%){ }^{21}$

\section{Pre-Operative Sedatives}

Bond et al with controlled extraocular muscle tension found the impact on \%OCR more with pre-operative intranasal dexmedetomidine $(-34 \%)$, than oral midazolam $(-29 \%)$ and least with no pre-operative sedation $(-20 \%) .{ }^{125}$ From initial OCR $86 \pm 16$ (percent of baseline HR induced by 10 -second, 200 gram square wave tension) to second EOM $66 \pm 25 \%$ with dexmedetomidine $0.5 \mu / \mathrm{Kg}$ IV between in 33 young patients was a significant augmentation compared to a non-opioid control group of 842 age-matched patients with first EOM $75 \pm 25 \%$ and second EOM $77 \pm 22 \%$ with no sedative in between. ${ }^{131}$ Jean et al reviewed regional anesthesia for eyes suggesting that dexmedetomidine "increases local anesthetic potency and prolongs duration of analgesia without an increase in adverse events." 132 In a retrospective study of strabismus surgery in children, the 34 who received pre-induction IV 
midazolam were 3.6 times less likely to have $20 \%$ OCR than the 52 who did not get it. ${ }^{85}$

\section{Antiemitics}

Wachta randomized half of their patients to droperidol with minimal impact on OCR. ${ }^{66}$

\section{Dexamethasone}

Compared to median OCR of $85 \%$ of pre-heart rate in 2527 initial cases, dexamethasone increased bradycardia with OCR to $72 \%$ of pre heart rate in 1898 patients. ${ }^{21}$ In this Alaska OCR study, the confounding factor may be the one prominent anesthesiologist with dominant average OCR frequently used IV push fentanyl with dexamethasone.

\section{ASA of the Patient}

All patients in some studies are ASA I. ${ }^{74}$ Fourteen of 86 strabismus children had chronic diseases cerebral palsy and asthma and were ASA II, but they did not have increased risk of OCR $(\mathrm{p}=0.08)$ by regression analysis. ${ }^{85}$

\section{Recovery Issues PONV}

In some studies, the presence of OCR did not help predict postoperative nausea and vomiting (PONV). ${ }^{51,65,133}$ On the other hand, Allen found that the patients with OCR had a 2.6 times increased likelihood of PONV. ${ }^{63}$ Wachta, ${ }^{66} \mathrm{Juhel}^{134}$ and Wilhelm ${ }^{135}$ found the (TIVA) propofol group compared to inhalational had more OCR but less PONV. ${ }^{66,134}$ Persistent nausea and vomiting accompanied bradycardia and somnolence in a child with rapidly changing orbital mass. ${ }^{136} \mathrm{PONV}$ was similar comparing ondansetron timing with OCR requiring atropine or not. ${ }^{137}$ Diazepam plus atropine before strabismus surgery produced a low rate of PONV and OCR. ${ }^{138}$ Karanovic et al did not alter the rate of PONV despite rocuronium that reduced OCR. ${ }^{118}$ Dexamethasone with or without ondansetron has been used to reduce PONV. ${ }^{139}$ Slow infusion dexmedetomidine may reduce PONV after strabismus surgery in children. ${ }^{84}$

\section{Post-Op Pain}

There was more post-op pain with fentanyl IV than with post-strabismus surgery sub-tenon's block. ${ }^{25}$ Ducloyer et al noted $27 \%$ post-op pain with strabismus and only 9\% with other eye procedures including Botox injection and cataract. ${ }^{139}$ Postoperative pain and PONV was no different between strabismus patients whether or not they had $-33 \%$ OCR. ${ }^{86}$

\section{Influence of Ophthalmic Surgeon} Orbital Block

In one study, peribulbar block failed to abolish $\mathrm{OCR}^{46}$ contrary to a recent review of the topic. ${ }^{132}$ Indeed, many have found orbital block very effective in reducing or preventing OCR. ${ }^{34,48,52,56,140,141}$ Peribulbar block reduced OCR and PONV during vitreoretinal surgery in children. ${ }^{142}$ Peribulbar ropivacaine with IV propofol/remifentanil general anesthesia for retinal detachment produced only 6 of 31 OCR compared to $17 / 31$ with placebo saline injected into the lower lid. ${ }^{112}$ If pain is required to maintain blood pressure through adrenergic stimuli, a block could lead to hypotension. ${ }^{143}$ Orbital block eliminated the vagal and sympathetic reflexes with high (600 gram) prolonged EOM tension. ${ }^{90}$ Peribulbar lidocaine block in retina patients reduced 400-gram tension OCR to $13 \%$ compared to nitrous-narcotic general anesthesia OCR rate at $53 \%{ }^{50} \mathrm{In}$ a small RCT, peribulbar lidocaine reduced OCR during medial rectus surgery, no OCR was noted during delivery of the block or the topical lidocaine control group. ${ }^{23}$ Subtenons block in 100 vitreoretinal pediatric surgical cases had less OCR (5\%) randomly compared to 100 with IV fentanyl $(32 \%){ }^{25}$ Sub tenons bupivacaine and lidocaine caused 5\% OCR while IV fentanyl had 20\% OCR in pediatric cataract surgery. ${ }^{144}$ Subtenons bupivacaine and IV or per rectum paracetamol produced similar $20-23 \%$ bradycardia to less than $60 \mathrm{bpm} .{ }^{26}$ Infratrochlear block reduced OCR defined as more than $15 \%$ bradycardia from $38 \%$ to $10 \%$ with planned EOM tension. ${ }^{69}$ Analyzing $\mathrm{n}=264$ patients from several randomized clinical trials of orbital block, a $35 \pm 26 \%$ reduction in incidence of OCR was accomplished with the block.

\section{Local Anesthesia}

Mendelblatt added local anesthesia to retrobulbar or atropine in an early study of OCR. ${ }^{34}$ Peribulbar bupivacaine in retinal surgery had $30 \%$ OCR compared to $70 \%$ with morphine IV. ${ }^{145}$ Similarly, peribulbar bupivacaine had less OCR than IV meperidine in children ${ }^{146}$ and peribulbar bupivacaine had less OCR and PONV than placebo subtenons saline. ${ }^{121}$ Local anesthesia has been used for strabismus surgery. ${ }^{147}$ Subconjunctival injection produced $47 \%$ OCR while venipuncture only $9 \% .{ }^{148}$ Gupta et al compared topical $2 \%$ lidocaine ( $73 \%$ OCR) to peribulbar block $(13 \%)$ and none $(94 \%)$ in strabismic children. ${ }^{23}$ Peribulbar anesthesia had substantially less OCR and PONV compared to strabismus patients randomized to IV fentanyl. ${ }^{149}$ Periocular and even sub-tenon's block is 
more challenging in young children due to the relatively larger size of the globe. ${ }^{150}$ Bupivicaine injected into an eyelid before chalazion surgery caused asystole. ${ }^{151}$

\section{Topical Anesthesia}

Ruta found reduced OCR with medial rectus tension after topical application of lignocaine. ${ }^{152}$ In a subsequent randomized study of topical lidocaine vs saline 5 minutes before EOM tension in retina or strabismus surgery, OCR dropped from $86 \%$ to $37 \%$ but profound 10 -second asystole was reduced from $14 \%$ to $0 \%$ with the lidocaine. ${ }^{153}$ A prolonged OCR, greater in inferior rectus than lateral rectus and not associated with over-all high vagal tone despite myasthenia gravis as was documented with topical anesthesia after I.V. fentanyl. ${ }^{154}$ Topical lidocaine jelly plus nalbuphine during one-stage strabismus adjustment resulted in $0 \%$ OCR. ${ }^{155}$ Topical anesthesia was added to both arms of a sub-tenon block randomized controlled trial. ${ }^{25}$ Seijas et al were able to do 101 of 567 strabismus cases with topical anesthesia only needing atropine to treat OCR in three patients. ${ }^{156}$ Sinha et al randomized topical lidocaine gel to proparacaine drops for 5 minutes before non-tension-monitored strabismus surgery in children finding no significant difference (57\% to $63 \%$ ) in OCR ${ }^{43}$ Rahimi et al randomized 70 strabismic children to liberal topical anesthesia versus none finding no change in EOM tension OCR but a reduction in bradycardia associated with conjunctival incision. ${ }^{87}$

\section{Manipulation of Extraocular Muscle \\ Lid Speculum}

Eustis found OCR with strabismus suture adjustment worse with lid speculum. ${ }^{61}$ Alphonso lid speculum plus scleral depressed retinal exam produces substantial bradycardia in premature infants. ${ }^{157}$

\section{Conjunctival Incision}

Loewinger found 7 of 30 strabismus patients had bradycardia $20 \%$ with conjunctival pull. ${ }^{75}$ Severe OCR was seen in 1 of 4 patients with conjunctival closure under topical anesthesia. ${ }^{158} \mathrm{Kim}$ and Shin found OCR (15\% bradycardia) of $7 \%$ with conjunctival manipulation compared to unquantified muscle traction of $38 \%{ }^{69}$ Rahimi et al described "the incision phase" which may include conjunctival and Tenon's capsule dissection which had 16\% incidence compared to greater $27 \%$ incidence during the "release phase" described as muscle manipulation.

\section{Muscle Dissection}

Kim and Shin noted highest incidence of 15\% bradycardia
OCR with muscle dissection $87 \%$ compared to incision $7 \%$ and medial rectus muscle traction $38 \%$ reduced to $20 \%, 3 \%$ and $10 \%$ in a group randomized to receive infratrochlear block. ${ }^{69}$ Shin et al measured ECG and heart rate during the 156-161 mean seconds between lateral rectus and medial rectus hook to EOM "release."5

\section{Which EOM}

The OCR from medial rectus (MR) was greater than from lateral rectus (LR) in several studies. ${ }^{19,55,58,73,76,117,127}$ OCR from superior rectus (SR) resembled MR with inferior rectus (IR) having more and LR having the least. ${ }^{107}$ Stump found mean and standard deviation heart rate decrease as follows: IR $-23 \pm 22 \%$, MR $-16 \pm 17 \%$, SR $-15 \pm 19 \%$, LR $-11 \pm 18 \% .{ }^{159}$ Ohashi noted decreasing OCR from medial rectus to inferior oblique to lateral rectus. ${ }^{37}$ Deacock found no difference between medial rectus, lateral rectus and inferior oblique muscles. ${ }^{54}$ Lai et al found similar OCR for MR and LR stimulated with gentle tension. ${ }^{105}$ Dornberger found more OCR with superior than lateral rectus. ${ }^{42}$ Anderson documented a triad of bradycardia, nausea and faintness associated with traction on the levator and lower lid retractors in 5 of 36 patients. ${ }^{108}$ OCR can be observed during blepharoplasty. ${ }^{160}$ Grover placed 25 -second, 400 gram tension on each EOM during retinal surgery in adults finding the order of bradycardia, from most to least as $\mathrm{IR}(22 \%)>\mathrm{SR}>\mathrm{LR}>\mathrm{MR}>\mathrm{SO}>\mathrm{IO}$. Aletaha found more OCR with cyclovertical muscles than horizontal noting that cyclovertical required more muscle traction. ${ }^{68}$ The second muscle in the case was suspected of having less OCR than the first. ${ }^{24}$ With uniform tension and no anticholinergic, OCR was consistently least with lateral rectus (median $89 \%$ of stable pretension HR), then medial rectus (87\%), then 1784 cases with inferior rectus $(85 \%)$ and the most OCR with superior rectus $(84 \%){ }^{22}$

\section{Laterality}

Matarasso suspected more bradycardia during blepharoplasty on the left eye. ${ }^{161}$ The Alaska OCR study has confirmed more \%OCR with the left eye than the right eye even though the left eye is usually operated first, however left predominance persisted in cases with single eye muscle surgery, too (Figure 9). A different neurologic eye condition with asymmetry exists with Duane's syndrome being more common in the left eye. ${ }^{162}$

\section{Tension Amount}

Increased tension caused more OCR. ${ }^{46}$ Blanc et al used 


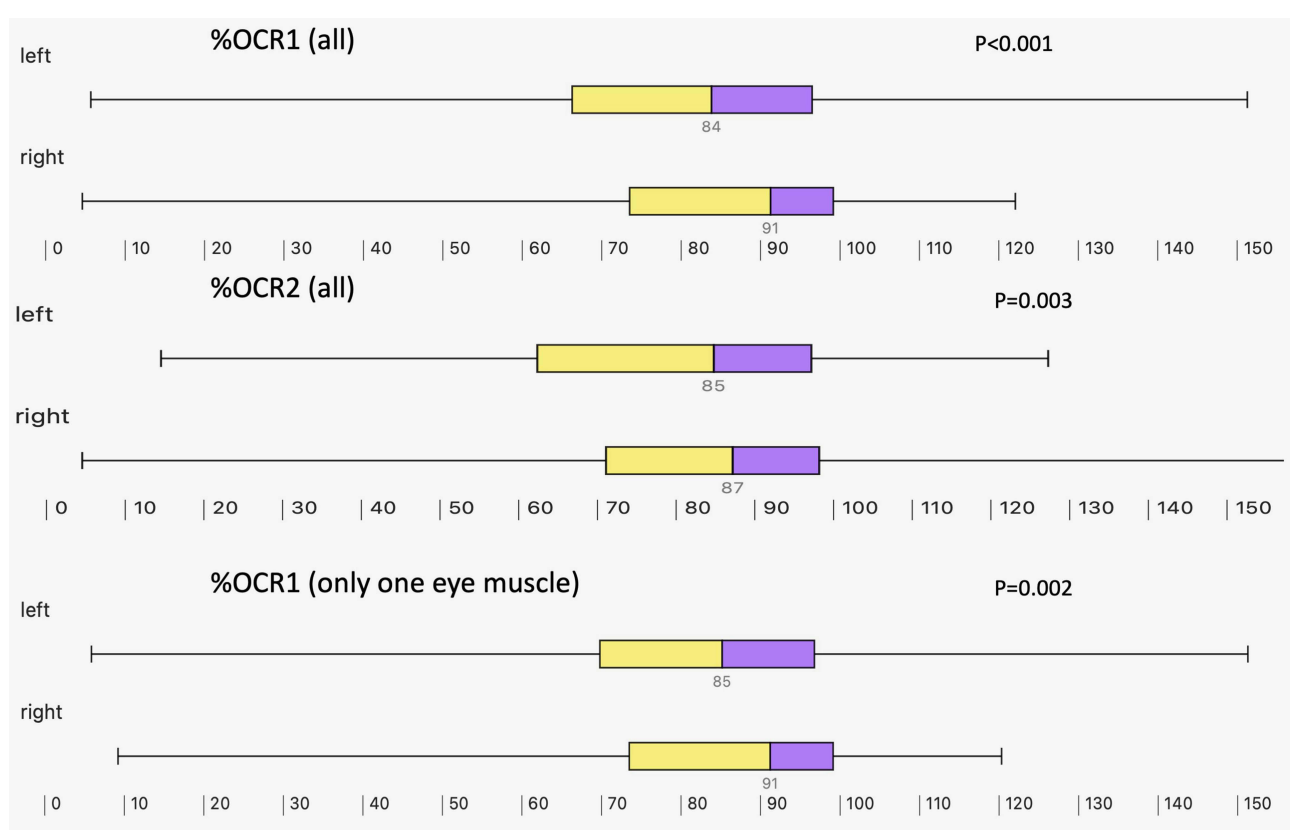

Figure 9 Laterality. The Alaska OCR study on two-eye cases usually performs the left eye first. For bilateral recordings, first eye, and also second eye had more \%OCR with the left eye, but this also was true for cases with only one-eye surgery.

300 gram tension. ${ }^{45}$ Ohashi et al noted increased OCR with tension increasing from 50 to 600 grams. $^{37}$ Hahnenkamp delivered 4-6 Newtons to the EOM. ${ }^{64}$ Braun et al utilized a firm 600 grams of tension in 25 infants and children. ${ }^{90}$ Lai et al used "minimal traction force" by an experienced strabismus surgery producing $37 \%$ OCR. ${ }^{105}$ Grover used 400 gram, 25 second tension on all extraocular muscles in a randomized trial during retinal surgery with the longest R-R interval 6.2 seconds. ${ }^{50}$ In rabbits, square wave tension produced progressive increased bradycardia starting at $19 \pm 8$ grams. ${ }^{163}$ Song et al utilized a single experienced senior surgeon presumed to deliver "comparable EOM tension." 20 A uniform 200 gram, 10-second square wave tension has been used in the Alaska OCR study. ${ }^{19,22,38,100,110,125,131,159,164}$ Machida found OCR $-18 \%$ with 400 gram, $-16 \%$ with 200 gram but significantly less $-10 \%$ for 50 gram tension. ${ }^{165}$

\section{Tension Duration}

Batterbury compared 150 gram to 500 gram square-wave tension for 20 seconds. ${ }^{46}$ Braun pulled 600 grams for 60 seconds $^{90}$ and Hahnenkamp 400-600 grams for 90 seconds. ${ }^{64}$ The Alaska OCR study utilizes a ten-second tension. $22,38,110,159,165$ Pratt found 63 patients with initial 10 -second, 200 gram tension and profound $(62 \pm 16 \%$ heart rate reduction) OCR then had prompt, subsequent brief 5 second 200 gram tension with less OCR $(49 \pm 20 \%$ heart rate reduction, $\mathrm{t}=6.8, \mathrm{p}<0.001){ }^{166}$

\section{Tension Wave Form}

Blanc found and found that square wave produced more OCR than gradual ramp-up pressure. ${ }^{45}$ Batterbury used 20 second and Grover 25 second $^{50}$ square-wave quantified tension. ${ }^{46}$ Quick traction produced $87 \%$ OCR versus progressive traction just 51\%. ${ }^{31}$ The Alaska OCR study uses a square wave tension waveform. ${ }^{38,159,165}$

\section{Fatigue}

Moonie found fatigue in OCR occurred only if a short interval ( $<6$ minutes) was between two tensions. ${ }^{94}$ Blanc also found fatigue with repeat OCR tension. ${ }^{45}$ Machida found that waiting 3 minutes after a profound initial EOM OCR produced a fatiguing $17 \%$ decrease (from $64 \%$ to $56 \%$ heart rate reduction) in OCR effect. ${ }^{165}$

\section{Simultaneous Tension on More Than One Muscle}

Pratt et al tested 182 consecutive patients with 10 -second, 200 gram square wave tension. ${ }^{166}$ Those with only one muscle tendon pulled had OCR heart rate reduction of 29 $\pm 24 \%$ which did not differ from tension on two adjacent rectus muscle tendons $(31 \pm 26 \%$, paired $\mathrm{t}=0.7, \mathrm{p}=0.49)$.

\section{Second or Subsequent EOM}

Karhunen found the second muscle less OCR than the 
first $^{73}$ as did Kilic and Gulec. ${ }^{24}$ Loewinger found $25 \%$ less OCR with second muscle, but some cases got atropine. ${ }^{75}$ Machida found controlled-tension, non-anticholinergic first EOM $-16.9 \pm 19 \%$ significantly more bradycardia than the second, paired EOM $-14.6 \pm 17 \%$ (paired $t$-Test $\mathrm{p}=0.0001) .{ }^{165} \mathrm{~A}$ rapid fall in heart rate with grasping posterior orbital tissue is a helpful guide in identifying and repairing slipped or lost extraocular muscles. ${ }^{167}$ The first EOM in the cases had more OCR $(63 \%)$ than the second EOM in the case (30\%). ${ }^{127}$ The Alaska OCR study found less \%OCR with second muscle than first, and gradually decreasing with more duration during the surgical procedure under general anesthesia (Figure 10).

\section{Re-Operation}

In 323 patients with one or more strabismus surgery reoperations a mean of 2.6 years apart, the difference between OCR was not different from age-matched normal patients; however, EOM and opioid adjusted re-operations correlated with the initial case $(\mathrm{r}=0.37){ }^{22}$

\section{Type of Strabismus}

Aletaha et al found similar OCR with various types of strabismus. ${ }^{68}$

\section{Muscle Suturing}

OCR due to Faden posterior fixation suture operation was similar to that with recess-resect procedures. ${ }^{168,169}$ Resections had more OCR than recessions or myectomy. ${ }^{127}$

\section{Disinsertion}

While EOM traction on single muscles produced a heart rate change from $125.1 \pm 16 \mathrm{bpm}$ to $89.9 \pm 24 \mathrm{bpm}(67.5$ $\pm 12 \%$ ), cutting the muscle brought heart rate to $114.9 \pm 19$ bpm or a percent of baseline of $91.3 \pm 10 \% .{ }^{127}$

\section{Other Eye Surgery}

OCR has been commonly observed in retinal detachment surgery. ${ }^{123,153}$ OCR has been observed with enucleation. ${ }^{102}$ Eyelid surgery including blepharoplasty ${ }^{161,170}$ and other facial muscle tension ${ }^{171}$ can cause a bradycardia reflex. Paciuc in Mexico carefully documented OCR in LASIK without sedation ${ }^{172}$ and with fentanyl sedation. ${ }^{32}$ Pulse oximeter monitoring during 532 adult intravitreal injections found $3.3 \%$ with asymptomatic $20 \%$ drop in heart rate. ${ }^{82}$ LASIK with OCR from 90 to $40 \mathrm{bpm}$ caused cancellation of the surgery. ${ }^{173}$ An atypical OCR ${ }^{174}$ or a heart attack with atrioventricular block occurred at the end of cataract surgery. ${ }^{175}$ About $2.6 \%$ of 2001 cataracts surveyed had

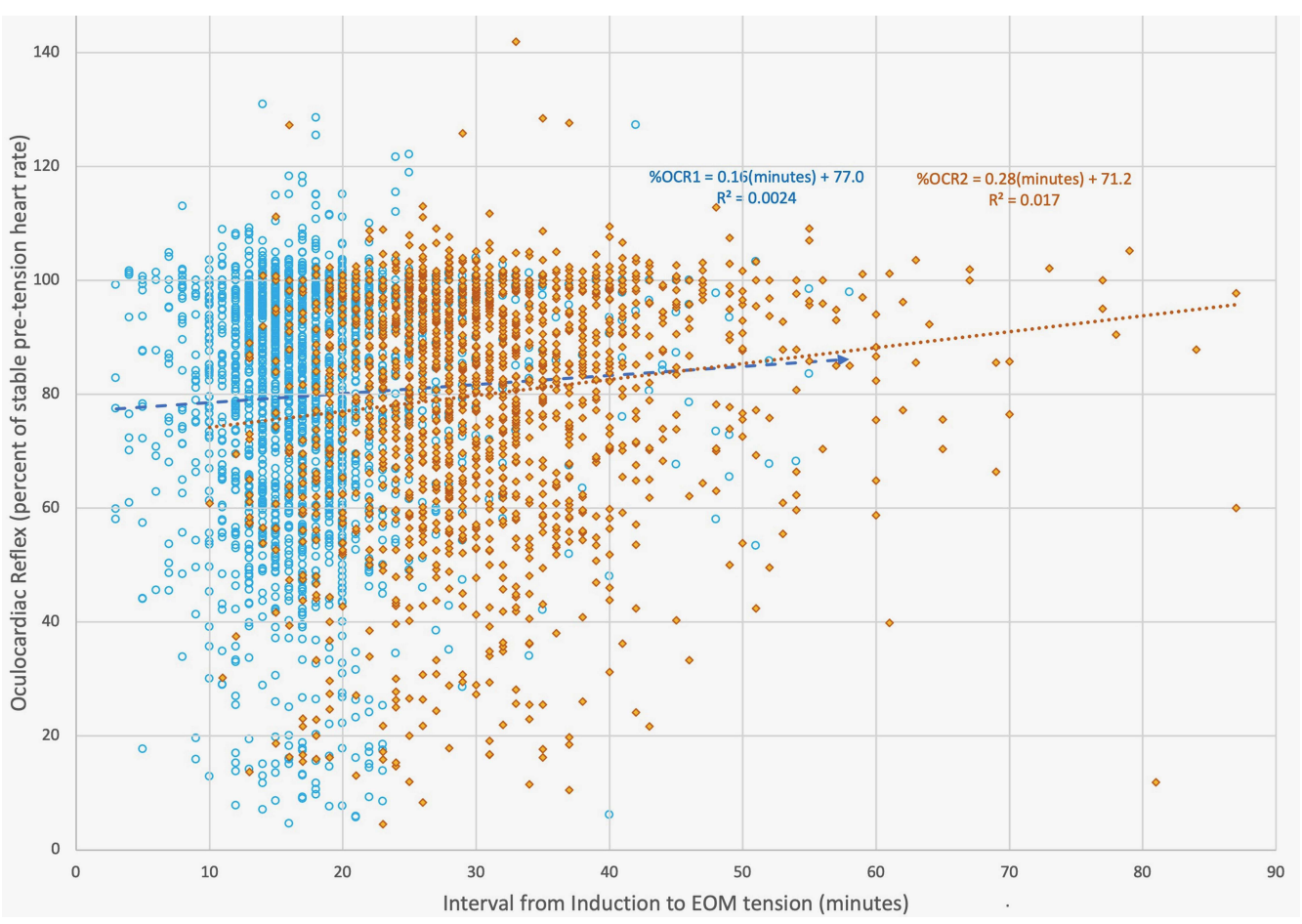

Figure 10 The correlations between the time interval between induction and EOM tension for first and second measurements of OCR produced by 10 -second, 200 gram square wave tension on rectus muscles. OCR is presented as percent of stable, pre-tension heart rate. First muscle cases indicated with blue circles and blue linear correlation while second muscle cases are shown in orange diamonds with orange linear regression. 
cardiac events of which $0.7 \%$ of cataract surgeries had intraoperative arrhythmias. ${ }^{176}$ Ghai et al found less OCR with subtenons local anesthesia than with IV fentanyl during pediatric cataract surgery. ${ }^{144}$ Ducloyer recently observed OCR during various pediatric eye surgery with dexamethasone and ondansetron PONV prophylaxis and an OCR incidence of 4 of 8 cataracts, 1 of 3 Botox EOM injections, and 34 of 52 strabismus cases. ${ }^{139}$

\section{Other Orbital/Trigeminal Manipulation}

OCR can be observed in about $17 \%{ }^{177}$ of orbital blowout fractures ${ }^{93,95,103,178}$ and is an indication for more urgent surgical intervention. ${ }^{179}$ OCR can also accompany zygomatic fracture, ${ }^{180,181}$ orbital tumor surgery, ${ }^{182,183}$ orbital hematoma, ${ }^{184}$ rapidly growing orbital mass, ${ }^{136}$ penetrating ocular trauma, ${ }^{185}$ midface disimpaction, ${ }^{186}$ maxillary and mandibular manipulation, ${ }^{187,188}$ forehead lift, ${ }^{189}$ endoscopic forehead lift ${ }^{190}$ and LaForte osteotomy. ${ }^{191}$ Heart rate can slow during intubation of an orbit. ${ }^{192}$ Even an empty orbit manipulated can cause OCR and asystole. ${ }^{193-196}$ Minor manipulation in the nose, especially with opioid may cause bradycardia. ${ }^{197}$ Opening the mouth during general anesthesia can cause bradycardia. ${ }^{198}$ If not familiar with trigeminovagal reflexes, cardiac pacemaker can precede repair of the inciting orbital fracture. ${ }^{104}$ Rhizotomy of the dorsal sensory roots of the trigeminal for intractable pain in a two year old produced asystole. ${ }^{199}$ Bradycardia may occur late after orbital floor fracture. ${ }^{200}$ Manipulation of the temporalis muscle during orbitozygomatic craniotomy produced reproducible, consistent asystole. $^{201}$

\section{Suture Adjustment}

Isenberg noted OCR with strabismus surgery suture adjustment. ${ }^{202}$ Vrabec blocked surgical OCR with atropine in 44 patients, but then noted heart rate drop to as low as 35 bpm during suture adjustment. ${ }^{60}$ In a survey, Eustis found 92 syncopal episodes from 37,096 strabismus surgery adjustments and one myocardial infarction. ${ }^{203}$ Eustis then had $65 \%$ OCR during surgery with 20\% later with adjustment and 3 of 20 with PVC during adjustment. ${ }^{61}$ Hertel et al adjusted 60 strabismus cases with 45\% having OCR of which 23 noted vasovagal symptoms. ${ }^{62}$ Hakim et al noted $0 \%$ during strabismus adjustment with lidocaine jelly. ${ }^{155}$ Of 4 adults with "asystole" during initial EOM surgery, subsequent adjustment cases resulted in two with $>20 \%$ OCR and one with severe OCR sitting up for adjustment and with conjunctival closure. ${ }^{158}$

\section{Trigeminal Stimuli}

Various branches of the trigeminal nerve elicit different cardiac reflexes. ${ }^{204}$ The oculocardiac reflex, or globe pressure has been proposed as a mechanism for sudden infant death syndrome (SIDS). ${ }^{205,206}$ A TrigeminoVagal (TVR) or trigeminocardiac reflex has been described. ${ }^{187,207-210}$

\section{Eye Examination}

An adult female with eye exam syncope did not have repeat bradycardia with some other trigeminal stimuli like supraorbital pressure. ${ }^{211}$ Syncope accompanied insertion of hard contact lenses. ${ }^{213}$

\section{ROP Examination}

OCR has been noted in premature infants. ${ }^{214}$ The heart rate change in $31 \%$ of infants can range from $10 \%-59 \%$ of baseline with various phases of the exam. ${ }^{215}$ Three of 80 premature ROP cryotherapy patients had respiratory arrest and one had cardiac arrest. ${ }^{216}$ Healthy premature babies monitored all night, and then subjected to globe pressure had mean lowest HR corresponding to $1049 \pm 540$ milli seconds with lowest HR (1894 ms R-R interval) being 32 bpm. ${ }^{217}$ Prakalapakorn and colleagues at Duke have shown more OCR with ophthalmoscopy than non-contact methods of ROP exam. ${ }^{218}$ Schumacher et al recorded ECG monitoring during lid speculum scleral depressed ROP exams in 281 infants (Figure 3) finding \%OCR ranged from $26 \%$ (bradycardia) to $149 \%$ tachycardia with a mean $64 \pm 4 \%$ finding that bradycardia during ROP exams was more rapid onset, greater median effect and longer duration than the bradycardia observed during strabismus surgery. ${ }^{157}$

\section{Influence by the Individual Patient Age}

Chong and Tan contradicted most reports by suspecting that adults may have more OCR than children. ${ }^{76}$ On the other hand, Tramer et al with separate, randomized clinical trials of OCR in adults ${ }^{77}$ and children ${ }^{91}$ observed more OCR with propofol in younger strabismic patients despite more atropine. Aletaha et al using 15\% HR change noted more OCR in patients less than 20 years and with baseline heart rates $>60 \mathrm{bpm}^{68}$ Young patients with subconjunctival injections had more bradycardia. ${ }^{148} \mathrm{Ha}$ et al used multivariate logistic to find less than a significant influence of age in 99 children. ${ }^{127}$ OCR defined as a percent of pretension was more prominent in younger patients determined by correlation. ${ }^{86,100}$ Pre-school compared to school 
age children had similar percent change OCR, but adults had less (Figure 3). ${ }^{22}$

\section{Gender}

There was no gender predilection with subconjunctival injection induced OCR. ${ }^{148} \mathrm{Kim}$ et al with only 16 patients and neural networks felt gender influenced $\mathrm{OCR}^{92}$ but Aletaha in an observation study of 76 patients found no gender predilection. ${ }^{68} \mathrm{Ha}$ et al found no influence by gender. ${ }^{127}$ No influence of gender on median OCR was found in our a large observational trial of over 2500 patients (Figure 3). ${ }^{22}$

\section{Race}

Caucasian strabismus patients seemed to have more OCR than other races with Alaska Natives, Blacks and Asians showing the least degree of bradycardia (Figure 3). ${ }^{22}$

\section{Iris Color}

In a deliberate study of 323 medical rectus strabismus cases, Fry studied his prior hunch ${ }^{114}$ that brown eyes had more $10 \mathrm{bpm}$ OCR finding $84 \%$ in brown eyes and $61 \%$ in blue eyes. ${ }^{49}$ Stump with deliberate uniform EOM tension found no difference in heart rate drop between 178 blue eyes $(-17 \pm 19 \%)$ and 249 brown eyes $(-15 \pm 19 \%) .{ }^{159}$ Iris color did not influence OCR (Figure 3). ${ }^{22}$

\section{Neurologic Status}

Tulip found a strong influence of neurologic status on OCR with traumatic brain injury producing more bradycardia and CNS infections the least. ${ }^{110}$ The influence on $\%$ OCR from various neurologic conditions is shown in Figure 11.

\section{Relatives}

OCR was observed in identical twin children undergoing same-day strabismus surgery. ${ }^{219}$ Twenty-eight first degree relatives had similar differences in uniformly elicited OCR to age-matched normals. ${ }^{22}$

\section{Re-Operation}

Apt found only $50 \%$ predictability in 5 cases of re-operation out of 243 patients in their series despite pre-op intramuscular atropine with "as much muscle tension as was safe." Tulip et al found in 152 strabismus re-operations $2.6 \pm 2$ years apart of whom 47 were not neurologically normal, those with initial profound 50\% OCR were $1.6 \mathrm{x}$ likely to have profound on re-operation and the first case correlated with re-operation $(p<0.001) .{ }^{110}$ Lai et al found the OCR from first EOM was highly predictive of OCR in second and third EOM in multiple muscle cases. ${ }^{105}$ More OCR was suspected in younger females and those with fine stereopsis and more EOM were operated. ${ }^{105}$ In 323 compared reoperations without anticholinergic, the difference between original case and subsequent was no different from agematched controls (Figure 3); however, re-operations in profound patients were more common than expected by chance. $^{22}$

\section{Prediction}

The 54 of 180 pediatric strabismus patients with greater than $20 \mathrm{bpm}$ OCR, time and frequency-domain and linear dynamic ECG indices and discriminant analysis could have predicted 39 of them. ${ }^{53}$

"OCR-Prone?:" Six patients with prior profound OCR during strabismus surgery did not have profound other vagal reflexes including diving response and globe pressure, but did have more heart rate change with carotid sinus massage. ${ }^{128}$ Patients with profound OCR are $1.6 \mathrm{x}$ more likely to be OCR prone on re-operation. ${ }^{110}$ One of 4 patients with recent asystole OCR had severe OCR on subsequent adjustment. ${ }^{158}$ Neurologic patients including traumatic brain injury and glaucoma patients were not additionally prone to globe pressure OCR. ${ }^{220}$ Of $9 \%$ with profound $50 \%$ OCR, those with re-operation were more likely ( $38 \%$ ) to repeat with profound OCR. ${ }^{22}$

\section{Neuroanatomy}

The orbital afferents and brain stem processing for trigemino-cardiac reflexes are reviewed by Buchholz et al. ${ }^{204}$ Concerning vagal efferents, a figure displaying the afferent and efferent neuroanatomy of OCR (Figure 4) is reproduced with permission from a 1994 publication. ${ }^{128}$

\section{Other Vagal Reflexes Compare with Diving Response (DR)}

In 183 professional and training divers, Valsalva Maneuver (VM) was compared to globe pressure (GP) with an alpha rhythm less than $9 \mathrm{c} / \mathrm{sec}$ correlating to positive globe pressure. ${ }^{221}$ In 15 subjects, temperature dependent apneic facial immersion had more bradycardia and was not predicted by globe pressure. ${ }^{222}$ Cold water irrigation to the eye producing bradycardia was thought to be DR instead of OCR. ${ }^{223}$ Surgical OCR has the widest intra-subject variability compared to other vagal maneuvers ranked by bradycardia as DR ( $57 \%$ HR), VM (75\% HR), CSM ( $83 \%$ HR), GP (91\%) with OCR (83\%). ${ }^{107}$ OCR and DR may 


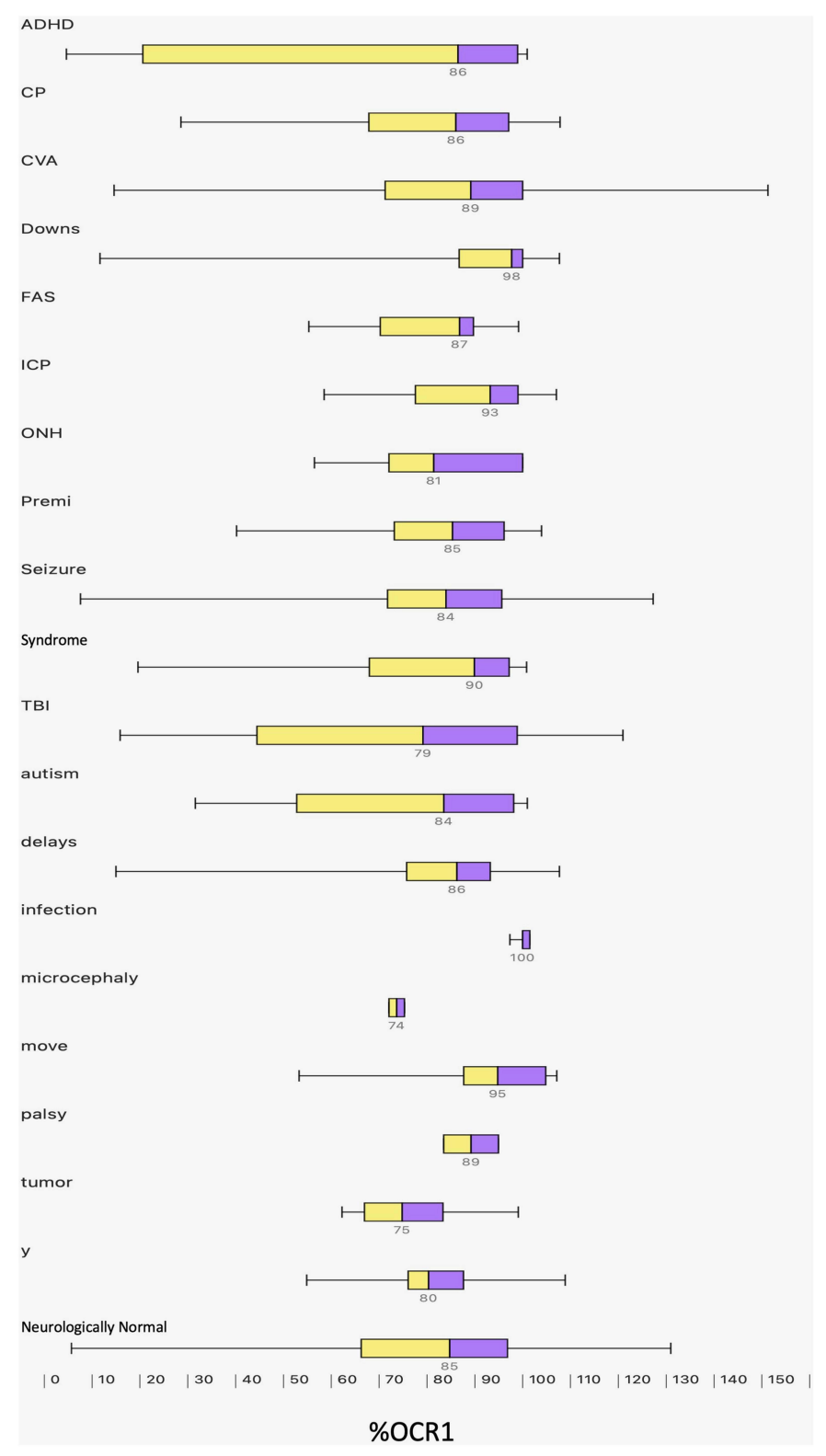

Figure II Influence on OCR by neurologic disorder: box (interquartile range with median in the middle and whisker ( 95 percentiles) of \%OCR for patients with various neurologic conditions from the Alaska OCR study. ADHD is attention deficit hyperactivity disorder, CP is cerebral palsy, CVA is stroke, FAS is fetal alcohol syndrome, ICP in elevated intracranial pressure, $\mathrm{ONH}$ is optic nerve hypoplasia, Premi is marked prematurity less than 2000 grams birthweight, TBI is traumatic brain injury, move disorder is myasthenia gravis or multiple sclerosis, $y$ is any neurologic disorder.

involve co-activation of sympathetic and parasympathetic innervation of the heart. ${ }^{224}$

\section{Globe Pressure (GP)}

OCR can occur with negative orbital pressure ${ }^{225}$ but tachycardia may also result. ${ }^{226}$ Globe pressure (GP) bradycardia blunted with maturity between premature and term infants ${ }^{40}$ and was used attempting to predict SIDS. ${ }^{227}$ Globe pressure $40-50 \mathrm{mmHg}$ rapidly produced a $10 \%$ average age-dependent heart rate drop compared to diving response slowly dropping $23 \%$ in
30 normal subjects. ${ }^{99}$ Ocular compression tests (GP) and thermal air stream (DR) in 10 healthy children found most bradycardia in the early morning hours. ${ }^{41}$ Globe pressure and diving response were not exaggerated in 6 patients with prior surgical profound OCR. ${ }^{128}$ Reyners et al tried to separate GP from DR producing bradycardia with more apnea. ${ }^{228}$ Standardized GP in sleeping neonates produced bradycardia and more central apnea during early quiet sleep phase. ${ }^{229}$ Globe pressure bradycardia may complicate breath-hold diving. ${ }^{230}$ Hamarat et al used sophisticated ramped up 
globe pressure from 0 to $48 \mathrm{mmHg}$ monitoring noninvasive intracranial pressure in glaucoma patients, neuro patients and normal subjects showing only $0.9 \%$ OCR $(10 \%$ bradycardia) with none reaching $20 \%$ bradycardia. $^{220}$

The oculocardiac reflex and some other vagal reflexes seem to lack the initial vasoconstriction that is a characteristic diving response; the mammalian diving response uniquely is preceded by vasoconstriction so that central mean arterial pressure is maintained. ${ }^{204}$

\section{Vagal Intensity and Arrhythmia}

In an adult $70 \mathrm{Kg}$ human, the sino-atrial (SA) node tissue automatically fires at about $70 \mathrm{bpm}$, the atrioventricular (AV) node automaticity about $45 \mathrm{bpm}$ and the ventricular tissue about $30 \mathrm{bpm} .{ }^{231}$ The SA node of a $2 \mathrm{Kg}$ infant fires at $160 \mathrm{bpm}^{232}$ The SA node of a hummingbird ranges from $100 \mathrm{bpm}$ on cold nights to $1260 \mathrm{bpm}$. A blue whale heart rate ranges from 2 to $37 \mathrm{bpm}$. The cardiac tissue with inherent automaticity can speed up with adrenergic nervous activity and can slow with cholinergic stimuli. Strong vagal reflexes like oculocardiac reflex can overpower the human cardiac automaticity to asystole of ten seconds and longer without premature nodal or ventricular beats in some patients.

\section{Multiple Authorship}

Several authors have written more than once regarding oculocardiac reflex. Two papers were written by Kirsch, ${ }^{18,34}$ Fessl-Alemany, ${ }^{106,233}$ Apivor and Ravi, ${ }^{36,234}$ Ge, ${ }^{235,236}$ Ghai $^{10,144}$ Klockgether-Radke, ${ }^{65,133}$ Tramér, ${ }^{77,91}$ Grover, ${ }^{50,237}$ Paciuc, ${ }^{82,172}$ and Mirakhur. $^{70,126}$ Fry wrote three papers. ${ }^{49,114,238}$ Four reports were written by Leonard Apt and Sherwin Isenberg. ${ }^{57,203,239,240}$ Meuwly et al have postulated about trigeminovagal reflexes. ${ }^{27,119,241}$

Karhunen did comparative trials of various different anesthetic agents. ${ }^{71,73}$ Blanc in Canada studied various anesthetic effects on OCR in children. ${ }^{45,51,111,242,243}$ Two different authors named Braun have studied OCR in Europe. $^{90,133,244}$

Yamashita wrote OCR reviews. $^{245,246}$

\section{IDEAL OCR Studies}

Braun et al started with no anticholinergic or opioid, reported consistent EOM tension and uniform OCR criteria but observed a relatively small number of children. ${ }^{90}$ Grover controlled extraocular tension on every EOM during a randomized controlled study of retinal surgery but with a small sample size. ${ }^{50}$ Allison et al avoided anticholinergic and had criteria $20 \%$ for OCR in a randomized trial comparing 1.3 MAC halothane to sevoflurane in 51 children but they lacked quantification of EOM tension. ${ }^{78}$ Goerlich in a randomized trial comparing sevoflurane to propofol in 180 children controlled opioid without anticholinergic with uniform $20 \%$ OCR criteria, but failed to quantify EOM tension. $^{79}$

Chung performed an RCT with each treatment arm 60 children comparing remifentanil to none with \%HR and $20 \%$ criteria OCR definition, but no EOM tension control. $^{39}$

Chhabra et al recruited sufficient patient numbers, randomized their study, defined OCR and used no anticholinergic, but muscle tension was not quantified by a nonblinded ophthalmologist. $^{25}$

The Alaska OCR avoids anticholinergic, reports opioids, and characterizes comparable \%HR criteria for OCR definition, and lists which EOM tensioned by how much and how long with large sample sizes, but the study is limited by its IRB approval as observational rather than the often-preferred randomized, double-blind controlled design. $^{117}$

The total number of patients studied: Excluding the 3127 patients from the Alaska OCR Studies, 12,035 patients were studied in 129 published reports including at least 51 randomized clinical trials each with median 75 patients ranging up to 822 patients (Table S1). An additional 48 from case reports have been also been published.

\section{Results}

A literature database related to oculocardiac reflex has been generated (Table S1).

The following are derived from analysis of the Alaska OCR Study database. There were a total of 3159 with 32 missing and 5 different initial tension, pacemaker 1, orbital block 5. Atropine was given before EOM tension in 169 of which 31 were re-ops. Non-atropine re-operation cases numbered 415. Original cases without anticholinergic numbered 2532.

The Alaska OCR Study controlled the following critical variables: anticholinergic, muscle tension, criteria for OCR while continually seeking sufficient sample size. Using examples from unpaired Student's $t$-Test, sample size: alpha 0.05 , power $80 \%$ Mean $80 \%$, S.D. $20 \%$. Sample size to detect a $20 \%$ difference: 16 in each 
cohort. Sample size to detect a 10\% difference: 63 in each cohort. Sample size to detect a $5 \%$ difference 251 in each cohort.

\section{Laterality}

The Alaska OCR study in symmetric cases often performs the left eye first. For first EOM, 2019 left eyes had OCR as percent of baseline HR median 84\% (Q1 66\%, Q3 96\%) more bradycardia than 482 right eyes (median 91\%, Q1 74\%, Q3 99\%, Mann-Whitney z=5.6, p<0.01, Figure 9). For second EOM, 297 left eyes (OCR 85\%, Q1 62\%, Q3 97\%) had more bradycardia than 1196 right eyes (median OCR 87\%, Q1 71\%, Q3 98\%, Mann-Whitney $z=2.9$, $\mathrm{p}<0.01)$. For cases with only single EOM, the 720 left eyes (OCR 85\%, Q1 70\%, Q3 97\%) still had more bradycardia than the 267 right eyes (OCR 91\%, Q1 73\%, Q3 99\%, Mann-Whitney $\mathrm{z}=3.1, \mathrm{p}<0.01$ ).

\section{Interval from Induction}

For the first EOM tensioned in each of 2056 non-anticholinergic, original cases, the median interval from initial anesthetic induction to EOM tension was 17 minutes (Q1 14 minutes, Q3 20 minutes, there was a correlation with Oculocardiac reflex as a percent of stable baseline heart rate Pearson correlation $\mathrm{r}(2054)=0.05, \mathrm{p}=0.03$ ). For the second EOM tensioned in 1623 cases, the median interval was 30 minutes (Q1 26 minutes, Q3 35 minutes) with significant correlation such that longer intervals were associated with less bradycardia (Pearson correlation $\mathrm{R}(1621)$ $=0.13, \mathrm{p}<0.01)$. Figure 10 shows the first and second oculocardiac reflex and the intervals from induction. For 1623 two EOM cases, the difference in time interval from first to second EOM did not correlate with the difference between OCR as a percent of stable baseline H.R. ( $\mathrm{r}(1623)$ $=-0.03, \mathrm{p}=0.18$ ).

\section{Decade of Study}

The impact of decade of experience for the Alaska OCR Study is shown in Figure 12. From study onset 1992 through 1999, most of the 949 cases had halothane and general endotracheal anesthesia with median OCR $88 \%$ (Q1 73\%, Q3 97\%). In the decade 2000-2009, 906 cases frequently had fentanyl on induction with initial median OCR 81\% (Q1 63\%, Q3 96\%) whereas the most recent 677 cases mainly with LMA anesthesia, sevoflurane and less induction opioids had median OCR 85\% (Q1 68\%, Q3 98\%). The difference between decades was significant (Kruskal-Wallis X2(2) $=24, \mathrm{p}<0.01)$.

\section{Rapid Onset}

We recently observed 418 patients with gradual onset (median 84\%, Q1 70\%, Q3 95\%) while 83 patients had rapid onset (median 58\%, Q1 38\%, Q3 73\%, changing more than $20 \%$ within the first two seconds after extraocular muscle tension (Figure 3). The difference in median response between these onset-separated groups was substantial (Mann Whitney $\mathrm{z}=8.1, \mathrm{p}<0.01$ ).

\section{Gender}

For 1262 males with initial, non-anticholinergic OCR 86\% (Q1 67\%, Q3 97\%) and 1270 females median OCR 85\%, Q1 68\%, Q3 97), there was no difference in percent heart rate effect (Mann-Whitney $\mathrm{z}=0.2, \mathrm{P}=0.85$, Figure 3 ).

\section{Neurologic Disorders}

The median percent OCR for 386 patients with neurological diseases 85\% (Q1 66\%, Q3 97\%) was slightly

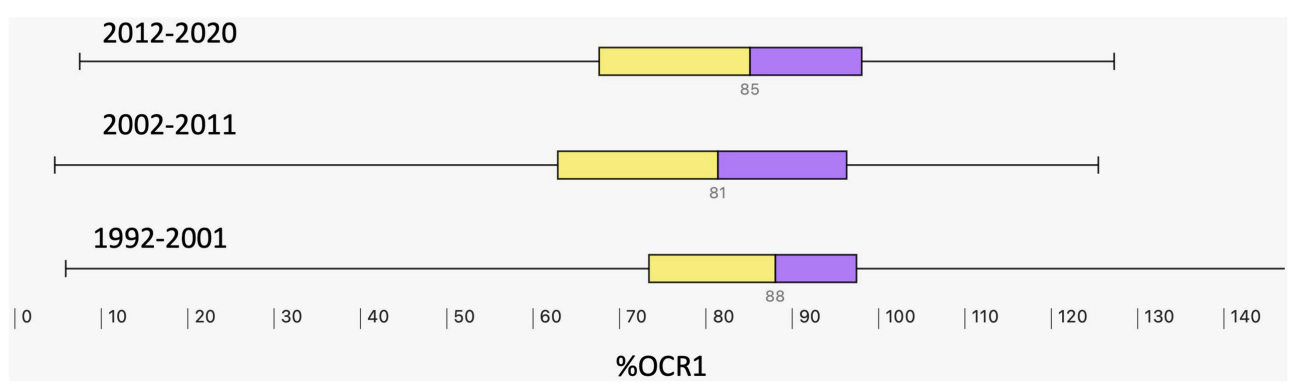

Figure 12 Influence of decade of experience; Box (interquartile range with median in the middle and whisker (95 percentile range) of \%OCR in the Alaska OCR study from first decade starting in 1992, second decade and almost full third decade. 
more bradycardia than 1894 patients with normal neurological exams (87\%, Q1 69\%, Q3 97\%, MannWhitney $\mathrm{z}=2.2, \mathrm{p}=0.03$, Figure 3 ). When separated down by classes of neurologic disorders with much smaller sample sizes that diminish power of conclusions, there still was a significant impact on \%OCR (Kruskal-Wallis X2(19) $=37, \mathrm{p}<0.01$ ). The median and quartile impact of various neurologic classes is given in Table 1 and shown in Figure 11. The entities showing most profound bradycardia are 53 patients with traumatic brain injury (TBI, median 78\%, Q143\%, Q3 $96 \%$ ) and 6 with CNS tumor (median 75\%, Q1 67\%, Q3 83\%).

\section{Anesthesiologists}

There was a significant impact by the routine selected anesthesia protocol by randomly assigned outpatient surgical anesthesiologist (Table 2 and Figure 13). For the main eleven anesthesiologists who each performed more than 60 cases without anticholinergic compared to all others, there was significant impact by individual (Kruskal-Wallis X2(11) $=91, \mathrm{p}<0.01)$. The anesthesiologist with least bradycardia did 98 cases with median \%OCR of 91\% (Q1 77\%, Q3 98\%). The maximum bradycardia for each of these eleven main anesthesiologists ranged from $\%$ OCR of $5 \%$ to $20 \%$. Of the eleven, the second most bradycardia (median \%OCR $78 \%$, Q1 60\%, Q3 91\%) was by one anesthetist who did 69 cases all of which had opiates ( 29 fentanyl, 5 hydromorphone and 35 a combination of fentanyl, hydromorphone or remifentanil) and $16(23 \%)$ received i.v. dexamethasone. The most median bradycardia (\% OCR of $67 \%$, Q1 $53 \%$, Q3 82\%) by one of the eleven main anesthesiologists did 150 cases mainly with sevoflurane or sevo/isoflurane and of which 129 (86\%) received intravenous fentanyl and 63 (42\%) received intravenous dexamethasone.

\section{Impact of Inhalational Agent}

From 1319 cases with general anesthesia maintained with desflurane median $94 \%$, halothane median $87 \%$, isoflurane median $89 \%$ and sevoflurane median $84 \%$, there was a significant difference in $\% \mathrm{OCR}$ due to agent type (Kruskal-Wallis $\left.\mathrm{X}^{2}(3)=18, \mathrm{p}<0.01\right)$. Except for desflurane and relatively smaller sample size, the degree of bradycardia with OCR decreased with deeper levels of inhaled agent (Figure 7).

\section{Impact of $\mathrm{CO} 2$ on $\mathrm{OCR}$}

In 2386 cases, \%OCR was inversely related to Expired $\mathrm{CO} 2$ concentration by the equation $\% \mathrm{OCR}=-0.13(\mathrm{CO} 2)$ +85.4 , slope confidence intervals -0.22 to $-0.04, \mathrm{p}<0.01$, Pearson's Product Moment $\mathrm{r}(2384)=-0.06, \mathrm{p}<0.01$, Figure 8).

\section{Impact of Rectus Muscle Type}

Comparing median \%OCR for lateral rectus $89 \%$, medial rectus $87 \%$, inferior rectus $85 \%$ and superior rectus $84 \%$, there was a significant difference due to muscle type (Kruskal-Wallis $\mathrm{X}^{2}(3)=8.1, \mathrm{p}=0.04$, Figure 3 ).

\section{Impact of Weight and Age}

The degree of bradycardia decreased with increasing patient weight (Pearson Product-Moment $\mathrm{r}(2125)=0.11$, $\mathrm{p}<0.001) . \%$ OCR1 $=0.071(\mathrm{CI} 0.04,0.1 ; \mathrm{p}<0.001)^{*}$ weight +76.6 (CI 75,78; $\mathrm{p}=0.001)$. Independently, weight and age correlated with \%OCR such that older, and heavier patients had less percent bradycardia (Figure 14); however, multivariable regression reduced the influence of weight but age was still significant.

\section{Multivariable Regression}

Multiple anesthetic variables impacting first muscle \%OCR were subjected to multivariable regression in 2441 patients. The opioid variables associated with a heart rate depressing impact were the hydromorphone $(-9.2, \mathrm{CI}-14,-4 ; \mathrm{p}<0.01)$, fentanyl $(-5.3, \mathrm{CI}-7,-3 ; \mathrm{p}<0.01)$ and remifentanil $(-10.3$, CI $-16,-4 ; \mathrm{p}<0.01)$. Other variables were inhalational agent $\mathrm{p}<0.01)$, nitrous oxide concentration $(0.06$, CI 0.03 , $0.09 ; \mathrm{p}<0.01)$, and muscle relaxant $(\mathrm{p}<0.01)$. Propofol did not have a significant impact $(-0.79, \mathrm{CI}-3,1.6 ; \mathrm{p}=0.51)$. Higher nitrous oxide independently reduced \%OCR (Pearson Product Moment $\mathrm{r}(2525)=0.07, \mathrm{P}<0.01)$. The difference between \%OCR-first muscle and \%OCR-second muscle was influenced by the difference in inhalational agent concentration $(2.3$, CI $0.6,4.1 ; \mathrm{p}<0.01)$ but not by the difference in exhaled $\mathrm{CO}_{2}(-0.1, \mathrm{CI}-0.3,0.1 ; \mathrm{p}=0.33)$.

\section{Dexamethasone}

In a recent report, we noted more oculocardiac reflex with intravenous dexamethasone for which we had no obvious reason. ${ }^{21}$ Dexamethasone independently produced more bradycardia, however with multivariable regression including anesthesiologists (Figure 13) and opioids (Figure 3), the dexamethasone effect was no longer significant. 
Table I Influence of Various Neurologic Conditions on Oculocardiac Reflex (Percent of Stable Baseline Heart Rate) Elicited by I0Second, 200 Gram Square Wave Tension with No Anticholinergic Medication

\begin{tabular}{|c|c|c|c|c|c|c|c|c|c|c|}
\hline Disorder & Count & Min & $5 \%$ & QI & Median & Q3 & $95 \%$ & Max & Mean & S.D. \\
\hline TBI & 38 & 16 & 19 & 43 & 78 & 96 & 102 & 108 & 71 & 28 \\
\hline Seizure & 29 & 8 & 34 & 71 & 82 & 91 & 105 & 127 & 79 & 23 \\
\hline Other & 31 & 5 & 21 & 72 & 83 & 99 & 101 & 109 & 81 & 23 \\
\hline Autism & 17 & 32 & 32 & 63 & 84 & 98 & 101 & 101 & 79 & 22 \\
\hline None & 2,069 & 6 & 38 & 66 & 85 & 97 & 102 & 131 & 80 & 21 \\
\hline Premi & 35 & 40 & 42 & 62 & 85 & 96 & 101 & 104 & 80 & 18 \\
\hline Delays & 17 & 15 & 15 & 76 & 86 & 91 & 103 & 103 & 78 & 24 \\
\hline $\mathrm{CP}$ & 57 & 29 & 44 & 68 & 86 & 97 & 102 & 108 & 80 & 20 \\
\hline FAS & II & 55 & 55 & 70 & 87 & 90 & 99 & 99 & 82 & 13 \\
\hline CVA & 23 & 15 & 15 & 69 & 87 & 100 & 111 & 119 & 79 & 28 \\
\hline Syndrome & 53 & 20 & 44 & 68 & 89 & 97 & 100 & 101 & 81 & 20 \\
\hline $\mathrm{ICP}$ & 18 & 59 & 59 & 78 & 93 & 99 & 107 & 107 & 89 & 13 \\
\hline Move disorder & 14 & 53 & 53 & 87 & 94 & 102 & 107 & 107 & 92 & 14 \\
\hline Downs & 39 & 12 & 39 & 85 & 97 & 100 & 107 & 108 & 90 & 19 \\
\hline
\end{tabular}

Notes: Minimum $=\min$ and maximum is max, $5 \%$ and $95 \%$ are percentiles while QI and Q3 are quartiles. S.D. is standard deviation. TBI is traumatic brain injury, Premi is premature, delays is developmental delay, CP is cerebral palsy, CVA is cerebral vascular accident, ICP is hydrocephalus, Syndrome is other genetic disorder other than Down syndrome, move disorder includes myasthenia gravis, multiple sclerosis and myotonic dystrophy.

\section{Extremes in Oculocardiac Reflex}

Figure 6 shows examples of some of the extremes in bradycardia associated with uniform extraocular muscle tension in the Alaska OCR study. At the onset of muscle tension, each patient has normal blood pressure and oxygen saturation. No adverse sequelae have resulted.

\section{Conclusion}

OCR still can surprise you! One patient in ten may have bradycardia to $50 \%$ of baseline heart rate or lower. Interventions by the anesthesiologist, the surgeon and characteristics of the patient themselves still do not lead to precise prediction of which patient might have a profound OCR or not.

Safe anesthesia for strabismus surgery can consider adequate doses of anticholinergic medication, or even orbital block, realizing each has potential adverse side effects. Insuring an adequate intravenous line and airway, and then sufficiently deep general anesthesia to avoid patient movement with ocular manipulation is helpful. If an IV is not available, atropine can be injected IM, but intraglossal route provides similar protection to intravenous, waiting 5-7 minutes before EOM tension after

Table 2 Influence of Anesthesiologists. The Eleven Main Anesthesiologists with More Than 60 Original Cases on Oculocardiac Reflex (Percent of Stable Baseline Heart Rate) Elicited by 10-Second, 200 Gram Square Wave Tension with No Anticholinergic Medication

\begin{tabular}{|c|c|c|c|c|c|c|c|c|c|c|}
\hline Anesthesia & Count & Min & $5 \%$ & Q I & Median & Q3 & $95 \%$ & Max & Mean & S.D. \\
\hline Doctor I & 150 & 6 & 16 & 53 & 67 & 82 & 101 & 118 & 66 & 24 \\
\hline Doctor 2 & 69 & 20 & 34 & 60 & 78 & 91 & 100 & 109 & 75 & 21 \\
\hline Doctor 3 & 152 & 12 & 28 & 59 & 81 & 97 & 102 & 105 & 76 & 24 \\
\hline Doctor 4 & 122 & 8 & 37 & 70 & 84 & 97 & 101 & 122 & 80 & 22 \\
\hline Doctor 5 & 129 & 5 & 27 & 64 & 84 & 96 & 101 & 112 & 77 & 23 \\
\hline Doctor 6 & 101 & 13 & 45 & 72 & 86 & 97 & 103 & 115 & 82 & 19 \\
\hline Doctor 7 & 90 & 13 & 47 & 69 & 86 & 96 & 102 & 129 & 81 & 20 \\
\hline Doctor 8 & 74 & 14 & 53 & 81 & 88 & 98 & 102 & 111 & 86 & 16 \\
\hline Doctor 9 & 110 & 6 & 17 & 70 & 89 & 97 & 103 & 117 & 80 & 24 \\
\hline Doctor 10 & 212 & 19 & 53 & 74 & 90 & 99 & 105 & 125 & 84 & 18 \\
\hline Doctor II & 98 & 9 & 42 & 77 & 91 & 98 & 101 & 107 & 84 & 20 \\
\hline Others & $\mathrm{I}, 144$ & 6 & 43 & 68 & 86 & 98 & 102 & $13 \mid$ & 81 & 21 \\
\hline
\end{tabular}

Notes: Minimum = min and maximum is $\max , 5 \%$ and $95 \%$ are percentiles while QI and Q3 are quartiles. S.D. is standard deviation. 


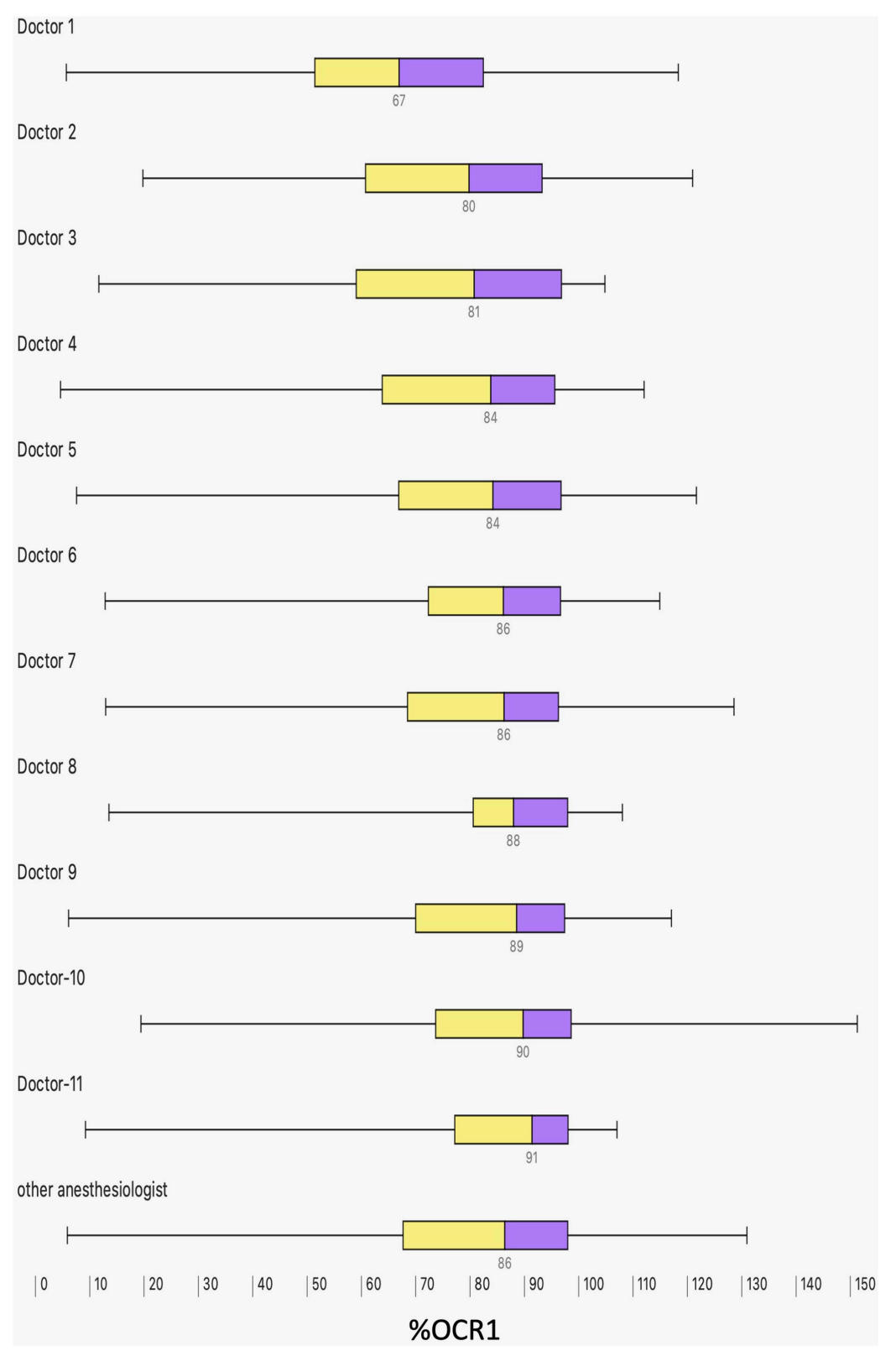

Figure 13 Influence of anesthesiologist. During the Alaska OCR study, the median, interquartile range (box) and 95 percentile range (whiskers) for \%OCR for the eleven anesthesiologists (Doc I through Doctor II) and all others (other anesthesia) who provided the most prolific coverage general anesthesia during planned, outpatient strabismus surgery showing their number of cases $(n=69-212)$.

baseline heart rate demonstrates anticholinergic-induced tachycardia. Before manipulation of ocular tissue or tension on the extraocular muscles, a stable heart rate, blood pressure and oxygen saturation should be attained. Gentle, gradual tension on the extraocular muscle tendons, and release of tension if bradycardia is elicited is one of the best therapies for OCR (Figure 15). Abrupt, prolonged tension on one or more EOM, especially in the left eye, and the inferior rectus or superior rectus muscle produces the most bradycardia. Recent doses of opioids and dexmedetomidine can profoundly augment OCR. IV dexamethasone may also enhance OCR and warrants further study. Unlike the diving response, OCR does not have concomitant peripheral vasoconstriction, so the strabismus surgical team should be prepared for hypotension during a profound OCR.

For uniform study of OCR, adequate sample size should be selected. Since there is a predictive relationship of the initial EOM tension OCR, to the subsequent tension (s) in the same case, patients may serve as their own 

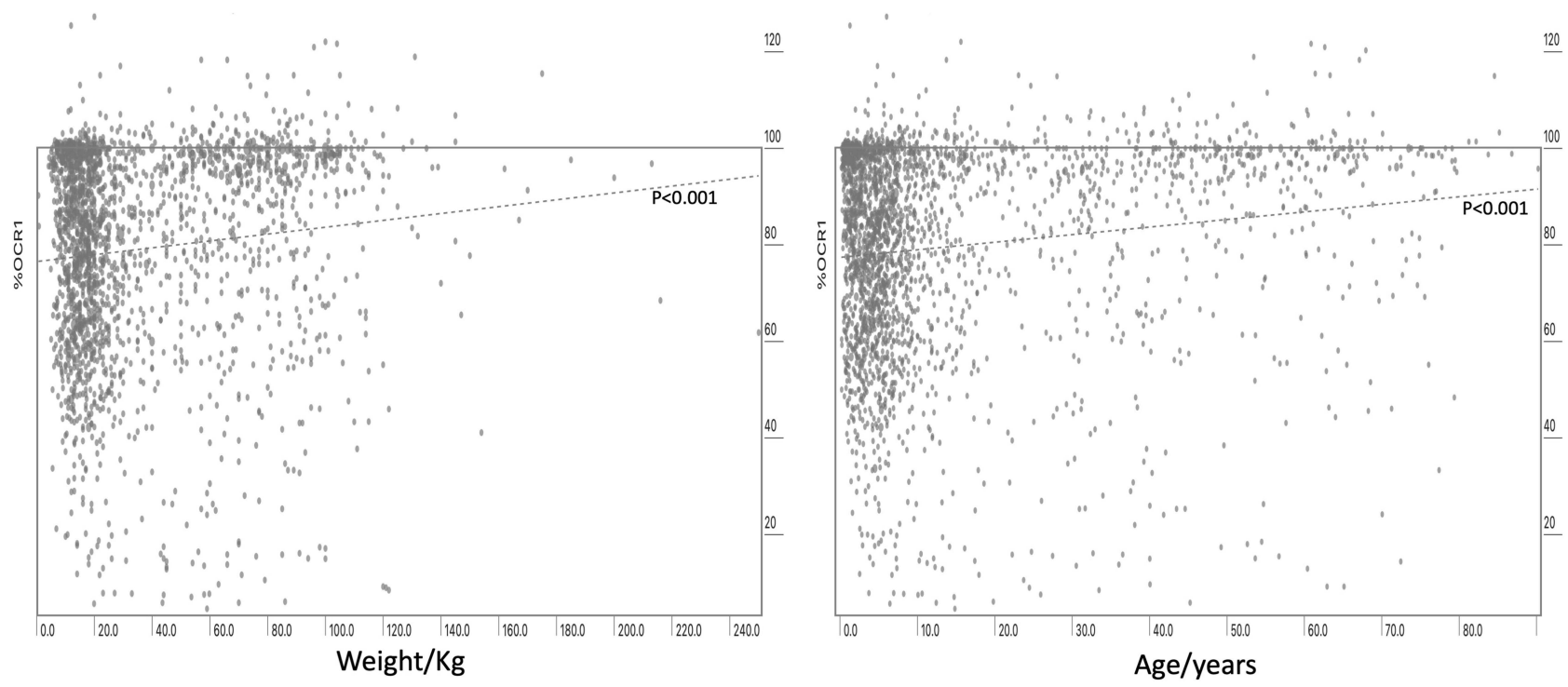

Figure 14 Influence of weight and age on \%OCR. There was a significant trend toward less \%OCR (no anticholinergic) for older and heavier patients during the Alaska OCR study. Multivariable regression found the correlation to be more robust for age than weight.

controls by administering the studied intervention between the first and second EOM, and comparing them to similar cases without the intervention, taking into account laterality. The criteria to define OCR should be uniform; a tension gauge should be used to ensure consistent tension; 200 grams is adequate for a firm pull on most EOM. Duration of pull matters, with 10 seconds capable of eliciting OCR even if the onset is gradual instead of rapid.

While the oculocardiac reflex during strabismus surgery can be strongly influenced by various aspects of general anesthesia, profound bradycardia can also accompany extraocular manipulation under topical anesthesia. As a result of this, it behooves the strabismus surgeon to exercise caution, even considering cardiac monitoring and supine positioning, during adjustable sutures for strabismus.
ROP: The bradycardia observed during lid speculum, scleral depressed indirect ophthalmoscopy is of more rapid onset, more profound degree, and of longer duration that the oculocardiac reflex during strabismus surgery (Figure 3), though the ROP babies rarely attain a heart rate less than $60 \mathrm{bpm}$ whereas strabismus surgery adults can have asystole of ten-seconds or more.

During some strabismus surgical cases under general anesthesia, and during ROP examinations oculocardiac reflex can be profound and with rapid onset. Median bradycardia with strabismus surgery is less than some other vagal reflexes; however, the profound OCR cases may have longer R-R intervals than even Valsalva maneuver or diving response. The vagal influence during profound OCR drives heart rate lower than ventricular inherent rate.

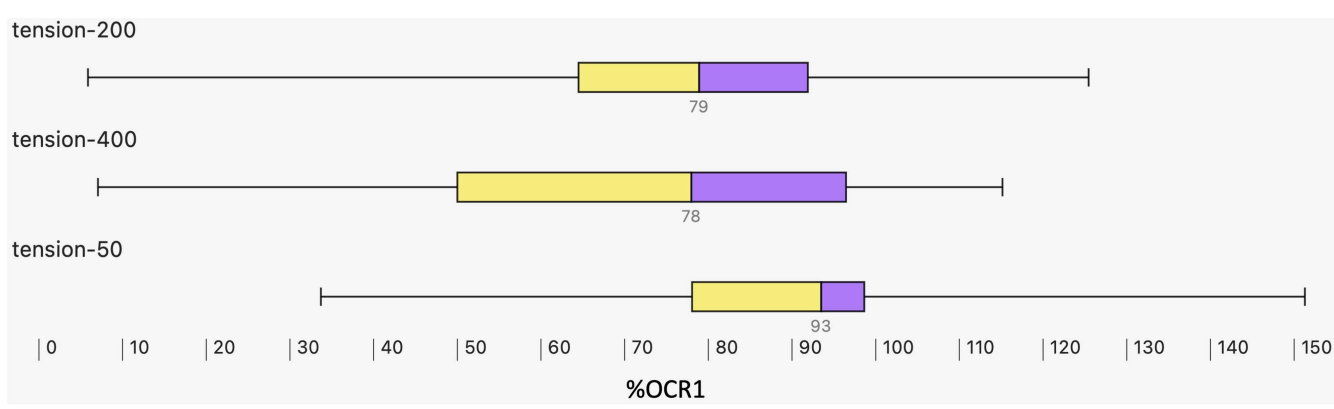

Figure 15 Impact of EOM Tension on \%OCR. The Alaska OCR study predominantly performs uniform 200 gram, 10 -second square wave tension on a carefully isolated extraocular rectus muscle (EOM). The median, the interquartile range (box) and 95 percentile (whiskers) for \%OCR elicited by 400 gram tension was similar to 200 gram tension, but significantly more than the minimal \%OCR elicited by very gentle, 50 -gram EOM tension. 
The oculocardiac reflex may not be consistently predictable, or preventable so the strabismus surgery team should be informed and prepared. Adequately powered randomized clinical trials that control both anesthetic and muscle manipulations are warranted. Perhaps, in the future, we will understand why such a reflex between eye and heart exists.

"I pray also that the eyes of your heart may be enlightened." Ephesians 1:18, NIV.

\section{Abbreviations}

$\mathrm{Bpm}$, beats per minute; $\mathrm{CI}$, confidence interval; $\mathrm{CO} 2$, carbon dioxide; CSM, carotid sinus massage; DR, diving response; EOM, extraocular muscle; GP, globe pressure; HR, heart rate; IM, intramuscular; IV, intravenous; LMA, laryngeal mask airway; N2O, nitrous oxide; OCR, oculocardiac reflex; ORR, oculorespiratory reflex; Q1 and Q3, interquartile ranges; PONV, post operative nausea and vomiting; PVC, premature ventricular contraction; RCT, randomized controlled trial; ROP, retinopathy of prematurity; SD, standard deviation; SIDS, sudden infant death syndrome; TIVA, total intravenous anesthesia; TVR, trigeminovagal reflex.

\section{Acknowledgments}

Alaska OCR study wishes to thank all the members of the institutional review board, the anesthesia teams, the research students and all the strabismus surgery patients who trusted us to protect their hearts and help them see straight.

\section{Funding}

There is no funding to report.

\section{Disclosure}

Financial disclosure: none related to OCR. Dr. Arnold is president and a board member of Glacier Medical Software which markets cloud-based ROP Check. He is also president and a board member of PDI Check which makes a vision screening game for the autostereoscopic screen on the Nintendo 3DS. Dr. Arnold coordinates the Alaska Blind Child Discovery which has received discounted vision screening technology from several vendors. Dr. Arnold is an investigator and protocol developer for the NIH-sponsored Pediatric Eye Disease Investigator Group. In addition, Dr Robert W Arnold has a patent PDI Check pending to Robert Arnold and Alex Damarjian; and is on non-paid advisory boards for PlusoptiX, GoCheck Kids, Adaptica and iScreen. The author reports no other potential conflicts of interest for this work.

\section{References}

1. vanBrocklin M, Hirons R, Yolton R. The oculocardiac reflex: a review. J Amer Optometric Assoc. 1982;53(5):407-413.

2. Scheiermann P, Herzog F, Siebenhofer A, Strametz R, Weberschock T. Intravenous versus inhalational anesthesia for pediatric inpatient surgery - A systematic review and meta-analysis. J Clin Anesth. 2018;49:19-25.

3. Dunville LM, Sood G, Kramer J. Oculocardiac Reflex (b); 2020. Available from: https://www.ncbi.nlm.nih.gov/pubmed/29763007. AccessedJune 4, 2021.

4. Doyle DJ, Mark PW. Reflex bradycardia during surgery. Can J Anaesth. 1990;37(2):219-222.

5. Shin SY, Kim MJ, Joo J. Oculocardiac reflex and oculorespiratory reflex during strabismus surgery under general anesthesia using the laryngeal mask airway with maintenance of spontaneous respiration: a retrospective study. J Int Med Res. 2020;48(8):1-10.

6. Singh GP, Prabhakar H, Ali Z. Is prevention or knowledge better than a cure for the trigeminal cardiac reflex? J Oral Maxillofac Surg. 2010;68(8):2035.

7. Lang SA, Van der Wal M. Death from the oculocardiac reflex [letter; comment]. Can J Anaesth. 1994;41(2):161.

8. Mallinson F, Coombes S. A hazard of anaesthesia in ophthalmic surgery. Lancet. 1960;1:574-575.

9. Fayon M, Gauthier M, Blanc VF, Ahronheim GA, Michaud J. Intraoperative cardiac arrest due to the oculocardiac reflex and subsequent death in a child with occult Epstein-Barr virus myocarditis. Anesthesiology. 1995;83:622-624.

10. Ghai B, Makkar JK, Arora S. Intraoperative cardiac arrest because of oculocardiac reflex and subsequent pulmonary edema in a patient with extraocular cysticercosis. Paediatr Anaesth. 2006;16(11):1194-1195.

11. Kroll HR, Arora V, Vangura D. Coronary artery spasm occurring in the setting of the oculocardiac reflex. J Anesth. 2010;24 (5):757-760.

12. Cooper J, Medow N, Dibble C. Mortality rate in strabismus surgery. J Am Optom Assoc. 1982;53(5):391-395.

13. Morley M, Menke AM, Nanji KC. Ocular Anesthesia-related closed claims from Ophthalmic Mutual Insurance Company 2008-2018. Ophthalmology. 2020;127(7):852-858.

14. Aschner B. Über einen bisher noch nicht beschriebenen Reflex vom Auge auf Kreislauf und Atmung. Verschwind des Radialpulses bei Druck auf das Auge. Wein Klin Wchnschr. 1908;44(Oct 29):1529.

15. Dagnini G. Intorno ad un riflesso provocato in alcuni emiplegici collo stimulo della cornea e colla pressione sul bulbo oculare. Boll Di Scienze Med. 1908;8:380.

16. Petzetakis M. Réflexe oculo-respiratoire et réflexe oculo-vasomoteur a l'état normal. Bull Soc Med Hosp Paris. 1914;37:816-822.

17. Bailey J. The oculocardiac reflex A report of a marked reaction following enucleation of the eyeball. Am J Ophthalmol. 1935;18:22-25.

18. Kirsch RE, Samet P, Kugel V, Axelrod S. Electrocardiographic changes during ocular surgery and their prevention by retrobulbar injection. AMA Arch Ophthalmol. 1957;58(3):348-356.

19. Arnold RW, Wolfe T, Albrecht W, et al. Continuous monitoring and control of end-tidal anesthetic agent and $\mathrm{CO} 2$ mitigates the oculocardiac reflex during strabismus surgery. Binoc Vis Strabismus Q. 1996;11(4):281-288.

20. McCourt EA, Wagner B, Jung J, et al. Validation of the CHOP model for detecting severe retinopathy of prematurity in a cohort of Colorado infants. Acta Ophthalmol. 2018;96(3):e404-e405. 
21. Arnold RW, Jansen SS, Glasionov J. Anesthetic impacts on the oculocardiac reflex: evidence from a large, observational study. Clin Ophthalmol. 2021;15:973-981.

22. Arnold RW, Rinner AR, Arnold AW, Beerle BJ. The impact of reoperation, relatives and race on the oculocardiac reflex. Clin Ophthalmol. 2020;14:4253-4261.

23. Gupta N, Kumar R, Kumar S, Sehgal R, Sharma KR. A prospective randomised double blind study to evaluate the effect of peribulbar block or topical application of local anaesthesia combined with general anaesthesia on intra-operative and postoperative complications during paediatric strabismus surgery. Anaesthesia. 2007;62(11):1110-1113.

24. Bajares AC, Anselmi A, Capriles MA. The association between surgical technique and oculocardiac reflex in pediatric strabismus surgery. Brazilian J Anesthesiol. 2021;71.

25. Chhabra A, Sinha R, Subramaniam R, Chandra P, Narang D, Garg SP. Comparison of sub-Tenon's block with i.v. fentanyl for paediatric vitreoretinal surgery. Br J Anaesth. 2009;103(5):739-743.

26. Ibrahim AN, Shabana T. Sub-Tenon's injection versus paracetamol in pediatric strabismus surgery. Saudi J Anaesth. 2017;11 (1):72-76.

27. Meuwly C, Chowdhury T, Sandu N, Golanov E, Erne P, Rosemann T. Definition and Diagnosis of the Trigeminocardiac Reflex: a Grounded Theory Approach for an Update. Front Neurol. 2017;8:533.

28. Richmond FJ, Johnston WS, Baker RS, Steinbach MJ. Palisade endings in human extraocular muscles. Invest Ophthalmol Vis Sci. 1984;25(4):471-476

29. Foster GE, Sheel AW. The human diving response, its function, and its control. Scand J Med Sci Sports. 2005;15(1):3-12.

30. Rhode J, Grom E, Bajares AC, Anselmi A, Capriles MA, Rivas C. A study of the electrocardiographic alterations occurring during operations on the extraocular muscles. Am J Ophthalmol. 1958;46(3 Pt 1):367-382.

31. Milot JA, Jacob JL, Blanc VF, Hardy JF. The oculocardiac reflex in strabismus surgery. Can J Ophthalmol. 1983;18 (7):314-317

32. Paciuc M, Mendieta G, Naranjo R, Angel E, Reyes E. Oculocardiac reflex in sedated patients having laser in situ keratomileusis. J Cataract Refract Surg. 1999;25(10):1341-1343.

33. Dowgird M. [Aschner's cardio-ocular reflex and its importance in eye surgery]. Klin Oczna. 1994;96(4-5):171-173.

34. Mendelblatt F, Kirsch R, Lemberg L. A study comparing methods of preventing the oculocardiac reflex. Am J Ophthalmol. 1962;53:506-512.

35. Berler D. The oculocardiac reflex. Am J Ophthalmol. 1963;56:954-959.

36. Apivor D, Ravi P. Ketamine and the oculocardiac reflex. Dysrythmia in pediatric strabismus surgery: the role of intravenous atropine. Anaesthesia. 1976;31:18-22.

37. Ohashi T, Kase M, Yokoi M. Quantitative analysis of oculocardiac reflex by traction on human extraocular muscle. Invest Ophthalmol Vis Sci. 1986;27:1160-1164.

38. Arnold RW, Farah RF, Monroe G. The attenuating effect of intraglossal atropine on the oculocardiac reflex. Binocul Vis Strabismus Q. 2002;17(4):313-318.

39. Chung CJ, Lee JM, Choi SR, Lee SC, Lee JH. Effect of remifentanil on oculocardiac reflex in paediatric strabismus surgery. Acta Anaesthesiol Scand. 2008;52(9):1273-1277.

40. Ramet J, Praud JP, D'Allest AM, et al. Effect of maturation on heart rate response to ocular compression test during rapid eye movement sleep in human infants [published erratum appears in Pediatr Res 1989 Apr;25(4):368]. Pediatr Res. 1988;24(4):477480.

41. Ramet J, Hauser B, Waldura J, De Prins J. Circadian rhythm of cardiac responses to vagal stimulation tests. Pediatr Neurol. 1992;8(2):91-96.
42. Dornberger I, Quast D, Velhagen KH, Bellach J, Guckler A. [The oculocardiac reflex during vitrectomy under neuroleptanalgesia]. Anaesthesiol Reanim. 1991;16(2):94-106.

43. Sinha R, Chandralekha BM, Ray BR, Mohan VK, Saxena R. A randomised comparison of lidocaine $2 \%$ gel and proparacaine $0.5 \%$ eye drops in paediatric squint surgery. Anaesthesia. 2013;68(7):747-752.

44. Yi C, Jee D. Influence of the anaesthetic depth on the inhibition of the oculocardiac reflex during sevoflurane anaesthesia for paediatric strabismus surgery. Br J Anaesth. 2008;101(2):234-238.

45. Blanc V, Hardy J-F, Milot J, Jacob J-L. The oculocardiac reflex: a graphic and statistical analysis in infants and children. Can Anaesth Soc J. 1983;30(4):360-369.

46. Batterbury M, Wong D, Williams R, Kelly J, Mostafa SM. Peribulbar anaesthesia: failure to abolish the oculocardiac reflex. Eye. 1992;6:293-295.

47. Welhaf W, Johnson D. The oculocardiac reflex during extraocular muscle surgery. Arch Ophthalmol. 1965;73:43-45.

48. Pöntinen PJ. The importance of the oculocardiac reflex during ocular surgery. Acta Ophthalmol. 1966;86(suppl):5-66.

49. Fry E, Hall-Parker J. Eye hue and the oculocardiac reflex. Brit $J$ Ophthalmol. 1978;62:116-117.

50. Grover V, Bhardwaj N, Shobana N, Grewal S. Oculocardiac reflex during retinal surgery using peribulbar block and nitrous narcotic anesthesia. Ophthalmic Surg Lasers. 1998;23(3):207-212.

51. Blanc V, Ruest P, Brisson G, Jacob J-L. Serum gastrin and blood glucose levels during halothane-nitrous oxide anaesthesia and strabismus surgery in children. Can J Anaesth. 1991;38(1):43-48.

52. Taylor C, Wilson F, Roesch R, Stoelting V. Prevention of the oculo-cardiac reflex in children: comparison of retrobulbar block and intravenous atropine. Anesthesiology. 1963;24 (5):646-649.

53. Kim HS, Kim SD, Kim CS, Yum MK. Prediction of the oculocardiac reflex from pre-operative linear and nonlinear heart rate dynamics in children. Anaesthesia. 2000;55(9):847-852.

54. Deacock AR, Oxer HF. The prevention of reflex bradycardia during ophthalmic surgery. Br J Anaesth. 1962;34:451-457.

55. Bosomworth P, Ziegler C, Jacoby J. The oculo-cardiac reflex in eye muscle surgery. Anesthesiology. 1958;19:7-10.

56. Reed H, McCaughey T. Cardiac Slowing during Strabismus Surgery. Br J Ophthalmol. 1962;46(2):112-122.

57. Apt L, Isenberg S, Gaffney W. The oculocardiac reflex in strabismus surgery. Am J Ophthalmol. 1973;76(4):533-536.

58. Hunsley J, Bush G, Jones C. A study of glycopyrrolate and atropine in the suppression of the oculocardiac reflex during strabismus surgery in children. Br J Anaesth. 1982;54:459-464.

59. Dewar K, Wishart H. The oculocardiac reflex. Proc Roy Soc Med. 1976;69:13-114.

60. Vrabec M, Preslan M, Kushner B. Oculocardiac reflex during manipulation of adjustable sutures after strabismus surgery. Am J Ophthalmol. 1987;104:61-63.

61. Eustis H, Eiswirth C, Smith D. Vagal responses to adjustable sutures in strabismus correction. Am $J$ Ophthalmol. 1992;114:307-310.

62. Hertle R, Granet D, Zylan S. The intraoperative oculocardiac reflex as a predictor of postoperative vaso-vagal responses during adjustable suture surgery. J Pediatr Ophthalmol Strabismus. 1993;30:306-311.

63. Allen L, Sudesh S, Sandramouli S, Cooper G, McFarlane D, Willshaw $H$. The association between the oculocardiac reflex and post-operative vomiting in children undergoing strabismus surgery. Eye. 1998;12(2):193-196.

64. Hahnenkamp K, Honemann CW, Fischer LG, Durieux ME, Muehlendyck H, Braun U. Effect of different anaesthetic regimes on the oculocardiac reflex during paediatric strabismus surgery. Paediatr Anaesth. 2000;10(6):601-608. 
65. Klockgether-Radke A, Demmel C, Braun U, Mühlendyck H. Erbrechen und okulokardiale reflex. Anaesthesist. 1993;42:356-360.

66. Watcha MF, Simeon RM, White PF, Stevens JL. Effect of propofol on the incidence of postoperative vomiting after strabismus surgery in pediatric outpatients. Anesthesiology. 1991;75(2):204-209.

67. Karanovic N, Jukic M, Carev M, Kardum G, Dogas Z. Rocuronium attenuates oculocardiac reflex during squint surgery in children anesthetized with halothane and nitrous oxide. Acta Anaesthesiol Scand. 2004;48(10):1301-1305.

68. Aletaha M, Bagheri A, Roodneshin F, Mosallaei M, Yazdani S. Oculocardiac Reflex during Strabismus Surgery: experience from a Tertiary Hospital. Strabismus. 2016;24(2):74-78.

69. Kim SH, Shin HJ. Effects of an infratrochlear nerve block on reducing the oculocardiac reflex during strabismus surgery: a randomized controlled trial. Graefes Arch Clin Exp Ophthalmol. 2018;256(9):1777-1782.

70. Mirakhur R, Jones C, Dundee J, Archer D. IM or IV atropine or glycopyrrolate for the prevention of oculocardiac reflex in children undergoing squint surgery. Br J Anaesth. 1982;54:1059-1063.

71. Karhunen U, Cozanitis D, Brander P. The oculocardiac reflex in adults: a dose response study of glycopyrrolate and atropine. Anaesthesia. 1984;39:524-528.

72. Mirakhur R, Shepherd W, Jones C. Ventilation and the oculocardiac reflex: prevention of oculocardiac reflex during surgery for squints: role of controlled ventilation and anticholinergic drugs. Anaesthesia. 1986;41(8):825-828.

73. Karhunen U, Nilsson E, Brander P. Comparison of four nondepolarizing neuromuscular blocking drugs in the suppression of the oculocardiac reflex during strabismus surgery in children. $\mathrm{Br} J$ Anaesth. 1985;57:1209-1212.

74. Queinnec MC, de Dieuleveult C, Chupin AM, Pinaud M. [Continuous propofol infusion versus enflurane in children operated on for strabismus. Comparison of the quality of anesthesia and recovery conditions]. Ann Fr Anesth Reanim. 1989;8(1):37-41.

75. Loewinger J, Friedmann-Neiger I, Cohen M, Levi E. Effects of atracurium and pancuronium on the oculocardiac reflex in children. Anesth Analg. 1991;73:25-28.

76. Chong J, Tan S. Oculocardiac reflex in strabismus surgery under general anesthesia- a study of Singapore patients. Singapore Med J. 1990;31:38-41.

77. Tramér M, Fuchs-Buder T, Sansonetti A, Rifat K. Low incidence of the oculocardiac reflex and postoperative nausea and vomiting in adults undergoing strabismus surgery. Can J Anaesth. 1997;44 (8):830-835.

78. Allison CE, De Lange JJ, Koole FD, Zuurmond WW, Ros HH, van Schagen NT. A comparison of the incidence of the oculocardiac and oculorespiratory reflexes during sevoflurane or halothane anesthesia for strabismus surgery in children. Anesth Analg. 2000;90(2):306-310.

79. Goerlich TM, Foja C, Olthoff D. [Effects of sevoflurane versus propofol on oculocardiac reflex-a comparative study in 180 children]. Anaesthesiol Reanim. 2000;25(1):17-21.

80. Oh JN, Lee SY, Lee JH, Choi SR, Chin YJ. Effect of ketamine and midazolam on oculocardiac reflex in pediatric strabismus surgery. Korean J Anesthesiol. 2013;64(6):500-504.

81. Karaman T, Demir S, Dogru S, et al. The effect of anesthesia depth on the oculocardiac reflex in strabismus surgery. $J$ Clin Monit Comput. 2016

82. Paciuc-Beja M, Meizner-Grezemkovsky D, Paciuc M, et al. Oculocardiac Reflex During Intravitreal Injection. Med Hypothesis Discov Innov Ophthalmol. 2020;9(2):111-117.

83. Zhu YL, Shen WH, Chen QR, et al. Desflurane anesthesia compared with total intravenous anesthesia on anesthesia-controlled operating room time in ambulatory surgery following strabotomy: a randomized controlled study. Chin Med J. 2020;133(7):779-785.
84. Li S, Liu T, Xia J, Jia J, Li W. Effect of dexmedetomidine on prevention of postoperative nausea and vomiting in pediatric strabismus surgery: a randomized controlled study. $B M C$ Ophthalmol. 2020;20(1):86.

85. Aydın BG, Küçükosman G, Pişkin Ö, et al. Factors Affecting Oculocardiac Reflex Incidence In Pediatric Strabismus Surgery: retrospective Study. JARSS. 2021;29(1):58-64.

86. Arnold RW, Bond AN. Does topical proparacaine improve postoperative comfort after strabismus surgery? Clin Ophthalmol. 2019;13:2279.

87. Rahimi Varposhti M, Moradi Farsani D, Ghadimi K, Asadi M. Reduction of oculocardiac reflex with Tetracaine eye drop in strabismus surgery. Strabismus. 2019;27(1):1-5.

88. Mizrak A, Erbagci I, Arici T, Avci N, Ganidagli S, Oner U. Dexmedetomidine use during strabismus surgery in agitated children. Med Princ Pract. 2011;20(5):427-432.

89. Snellen F, Vanacker B, VanAken H. Propofol-nitrous oxide versus thiopental sodium-isoflurane-nitrous oxide for strabismus surgery in children. J Clin Anesth. 1993;5:37-41.

90. Braun U, Feise J, Mühlendyck H. Is there a cholinergic and an adrenergic phase of the oculocardiac reflex during strabismus surgery. Acta Anaesthesiol Scand. 1993;37:390-395.

91. Tramér M, Sansonetti A, Fuchs-Buder T, Rifat K. Oculocardiac reflex and postoperative vomiting in paediatric strabismus surgery. A randomised controlled trial comparing four anaesthetic techniques. Acta Anaesthesiol Scand. 1998;42(1):117-123.

92. Kim WO, Kil HK, Lee JS, Lee JH. Prediction of oculocardiac reflex in strabismus surgery using neural networks. Yonsei Med J. 1999;40(3):244-247.

93. Mehmood N, Hasan A. Oculocardiac Reflex: an Underrecognized But Important Association With Orbital Trap Door Fractures. Pediatr Emerg Care. 2019.

94. Moonie G, Rees D, Elton D. The oculocardiac reflex during strabismus surgery. Can Anaesth Soc J. 1964;11(6):621-632.

95. Chelsey L, Shapiro R. Oculocardiac reflex during treatment of an orbital blowout fracture. J Oral Maxillofac Surg. 1989;47:522-523.

96. Smith RB, Douglas H, Petruscak J. The oculocardiac reflex and sino-atrial arrest. Can Anaesth Soc J. 1972;19(2):138-142.

97. Gold RS, Pollard Z, Buchwald IP. Asystole due to the oculocardiac reflex during strabismus surgery: a report of two cases. Ann Ophthalmol. 1988;20(12):473-477.

98. Galkowska I, Nizienska E. Cardiac arrest during ophthalmologica operations. Anaesth Resusc Intensive Ther. 1975;3(2):197-200.

99. Arnold RW, Dyer JA, Gould AB, Hohberger GG, Low PA. Sensitivity to vasovagal maneuvers in normal children and adults. Mayo Clin Proc. 1991;66(8):797-804.

100. Arnold RW, Bond AN, McCall M, Lunoe L. The oculocardiac reflex and depth of anesthesia measured by brain wave. $B M C$ Anesthesiol. 2019;19(1):36.

101. Alexander J. Reflex disturbances of cardiac rhythm during ophthalmic surgery. Brit J Ophthalmol. 1975;59:518-524.

102. Munden PM, Carter KD, Nerad JA. The oculocardiac reflex during enucleation [letter]. Am J Ophthalmol. 1991;111(3):378-379.

103. Sires B, Stanley R. Oculocardiac reflex caused by orbital floor trapdoor fracture: an indication for urgent repair. Arch Ophthalmol. 1998;116(7):955-956.

104. Kosaka M, Asamura S, Kamiishi H. Oculocardiac reflex induced by zygomatic fracture; a case report. J Craniomaxillofac Surg. 2000;28(2):106-109.

105. Lai YH, Hsu HT, Wang HZ, Cheng KI, Wu KY. The oculocardiac reflex during strabismus surgery: its relationship to preoperative clinical eye findings and subsequent postoperative emesis. $J$ AAPOS. 2014;18(2):151-155.

106. Fessl-Alemany E, Wegehaupt R. [The paradoxical oculocardial reflex and its treatment with pindolol (Visken)]. Albrecht Von Graefes Arch Klin Exp Ophthalmol. 1973;188(1):23-31. 
107. Arnold RW. The human heart rate response profiles to five vagal maneuvers. Yale J Biol Med. 1999;72(4):237-244.

108. Anderson R. The blepharocardiac reflex. Arch Ophthalmol. 1978;96:1418-1420.

109. Khurana I, Khurana AK, Singh PI, Gombar KK. Changes in arterial blood pressure during traction of extra-ocular muscles. A study in rabbits. Anaesthesia. 1992;47(7):574-578.

110. Tulip H, Norman M, Arnold RW. Oculocardiac reflex: re-operation and arterial blood pressure. J AAPOS. 2004;8(1): 100 .

111. Blanc V, Jacob J-L, Milot J, Cyrenne L. The oculorespiratory reflex revisited. Can J Anaesth. 1988;35(5):468-472.

112. Morel J, Pascal J, Charier D, et al. Preoperative peribulbar block in patients undergoing retinal detachment surgery under general anesthesia: a randomized double-blind study. Anesth Analg. 2006;102(4):1082-1087.

113. Brusilovskaia DA, Tumarkin BM. [Studies on the oculocardiac reflex with the use of arterial oscillography]. Vrach Delo. 1965;1:134-135.

114. Fry E, Hall-Parker J. Hyoscine butylbromide and the oculocardiac reflex. Brit J Ophthal. 1975;59:525.

115. Misurya V, Singh S, Kulshrestha V. Prevention of oculocardiac reflex (O.C.R.) during extraocular muscle surgery. Ind J Ophthal. 1990;38(2):85-87.

116. Gilani SM, Jamil M, Akbar F, Jehangir R. Anticholinergic premedication for prevention of oculocardiac reflex during squint surgery. J Ayub Med Coll Abbottabad. 2005;17(4):57-59.

117. Arnold RW, Jensen P, Kovtoun TA, Maurer SA, Schultz J-A. The profound augmentation of the oculocardiac reflex by fast-acting opioids. Binoc Vis and Strabismus Quart. 2004;19(4):215-222.

118. Karanovic N, Carev M, Ujevic A, Kardum G, Dogas Z. Association of oculocardiac reflex and postoperative nausea and vomiting in strabismus surgery in children anesthetized with halothane and nitrous oxide. Paediatr Anaesth. 2006;16(9):948954.

119. Meuwly C, Chowdhury T, Sandu N, Reck M, Erne P, Schaller B. Anesthetic influence on occurrence and treatment of the trigemino-cardiac reflex: a systematic literature review. Medicine. 2015;94(18):e807.

120. Forestner J, Imbrecht P. Controlled respiration does not inhibit oculocardiac reflex during strabismus surgery in children. Anesthesiology. 1983;59:A457.

121. Steib A, Karcenty A, Calache E, Franckhauser J, Dupeyron JP, Speeg-Schatz C. Effects of subtenon anesthesia combined with general anesthesia on perioperative analgesic requirements in pediatric strabismus surgery. Reg Anesth Pain Med. 2005;30 (5):478-483.

122. Liu Y, Zeng QY. [Sevoflurane-N2O inhalation anaesthesia with laryngeal mask airway and propofol-ketamine intravenous anaesthesia in strabismus surgery]. Zhong Nan Da Xие Xие Bao Yi Xиe Ban. 2006;31(1):97-99.

123. Lhuissier-Noel C, Gajdos A, Rousselie F, Fontaine M, Viars P. [Oculocardiac reflex in ocular surgery. Some means of prevention from consequences (author's transl)]. Anesth Analg. 1979;36(78):337-342.

124. Altom RL, Wright TE. Possible potentiation of trigeminal-vagal response by sufentanil [letter; comment]. J Oral Maxillofac Surg. 1990;48(7):770.

125. Bond AN, Beerle BJ, Arnold RW. Dexmedetomidine Nasal Sedation Produces More Oculocardiac Reflex During Strabismus Surgery. J Pediatr Ophthalmol Strabismus. 2016;53(5):318.

126. Mirakhur RK. Anaesthetic management of vitrectomy. Ann R Coll Surg Engl. 1985;67(1):34-36.

127. Ha SG, Huh J, Lee BR, Kim SH. Surgical factors affecting oculocardiac reflex during strabismus surgery. $B M C$ Ophthalmol. 2018;18(1):103.
128. Arnold RW, Gould AB, MacKenzie R, Dyer JA, Low PA. Lack of global vagal propensity in patients with oculocardiac reflex. Ophthalmology. 1994;101(8):1347-1352.

129. Espahbodi E, Sanatkar M, Sadrossadat H, Darabi Vafsi ME, Azarshahin M, Shoroughi M. Ketamine or atropine: which one better prevents oculocardiac reflex during eye surgery? A prospective randomized clinical trial. Acta Med Iran. 2015;53 (3): $158-161$

130. Dandoy M, Poisson F, Lampl E, et al. [Anesthesia using propofol during surgery of strabismus in children. A comparison of two different protocols of induction and maintenance]. Cah Anesthesiol. 1990;38(4):241-245.

131. Arnold RW, Biggs RE, Beerle BJ. Intravenous dexmedetomidine augments the oculocardiac reflex. $J$ AAPOS. 2018;22(3):211-213. e211.

132. Jean YK, Kam D, Gayer S, Palte HD, Stein ALS. Regional Anesthesia for Pediatric Ophthalmic Surgery: a Review of the Literature. Anesth Analg. 2019;14:458.

133. Klockgether-Radke A, Feldmann M, Braun U, Mühlendyck H. Droperidol vs Metoclopramid-Prophylaxie von Erbrechen nach strabismus-operationen bei Kindern. Anaesthesist. 1992;41:254259.

134. Juhel A, Chatellier-Miras A, Toulemont PJ, Le Callonnec A, Urvoy M, Malledant Y. [Comparative study of propofol versus thiopental-halothane in the occurrence of oculocardiac reflex and postoperative vomiting after surgery for strabismus in children]. Cah Anesthesiol. 1994;42(5):571-576.

135. Wilhelm S, Standl T. Bietet Propofol Vorteile gegenuber Isofluran fur die Sufentanil- supplementierte Anasthesie bei Kindern in der Strabismuschirurgie? Anasthesiol Intensivmed Notfallmed Schmerzther. 1996;31(7):414-419.

136. Westerling D, Blohme J, Stigmar G. Orbital mass in a child causing somnolence, nausea and bradycardia. Can J Anaesth. 1998;45(8):777-780.

137. Madan R, Perumal T, Subramaniam K, Shende D, Sadhasivam S, Garg S. Effect of timing of ondansetron administration on incidence of postoperative vomiting in paediatric strabismus surgery. Anaesth Intensive Care. 2000;28(1):27-30.

138. Özcan A, Günes Y, Haciyakupoglu G. Using diazepam and atropine before strabismus surgery to prevent postoperative nausea and vomiting: a randomized, controlled study. J AAPOS. 2003;7 (3):210-212.

139. Ducloyer JB, Couret C, Magne C, et al. Prospective evaluation of anesthetic protocols during pediatric ophthalmic surgery. Eur $J$ Ophthalmol. 2018;1120672118804798.

140. Yu XM, Wang LH. [The oculocardiac reflex during ocular operation under various anesthesia]. Chung Hua Yen Ko Tsa Chih. 1991;27(1):34-36

141. Mahfouz AK, Nabawi KS. Preemptive analgesia in rhegmatogenous retinal detachment surgery: is it effective? Retina. 2002;22 (5):602-606.

142. Subramaniam R, Subbarayudu S, Rewari V, Singh RP, Madan R. Usefulness of pre-emptive peribulbar block in pediatric vitreoretinal surgery: a prospective study. Reg Anesth Pain Med. 2003;28(1):43-47.

143. Griffis CA. The effect of intraoperative retrobulbar block on anesthetic management of enucleation under general anesthesia. Nurse Anesth. 1991;2(1):28-32.

144. Ghai B, Ram J, Makkar JK, Wig J, Kaushik S. Subtenon block compared to intravenous fentanyl for perioperative analgesia in pediatric cataract surgery. Anesth Analg. 2009;108(4):1132-1138.

145. Shende D, Sadhasivam S, Madan R. Effects of peribulbar bupivacaine as an adjunct to general anaesthesia on peri-operative outcome following retinal detachment surgery. Anaesthesia. 2000;55(10):970-975. 
146. Deb K, Subramaniam R, Dehran M, Tandon R, Shende D. Safety and efficacy of peribulbar block as adjunct to general anaesthesia for paediatric ophthalmic surgery. Paediatr Anaesth. 2001;11 (2): $161-167$.

147. Ostachowicz M, Burau J, Sadkiewicz A. The oculocardiac reflex during surgical correction of strabismus in local anesthesia. Ophthalmologica. 1965;150(4):259-262.

148. Kayikcioglu O, Kayikcioglu M, Erakgun T, Guler C. Electrocardiographic changes during subconjunctival injections. Int Ophthalmol. 1999;23(1):37-41.

149. Ramachandran R, Rewari V, Chandralekha C, Sinha R, Trikha A, Sharma P. Sub-Tenon block does not provide superior postoperative analgesia vs intravenous fentanyl in pediatric squint surgery. Eur J Ophthalmol. 2014;24(5):643-649.

150. Jean YK, Kam D, Gayer S, Palte HD, Stein ALS. Regional Anesthesia for Pediatric Ophthalmic Surgery: a Review of the Literature. Anesth Analg. 2020;130(5):1351-1363.

151. Katowitz WR, O’Brien M, Kiskis E, Elliott EM. An asystolic event after eyelid skin bupivacaine injection during chalazion surgery. J AAPOS. 2016;20(1):75-77.

152. Ruta U, Mollhoff T, Markodimitrakis H, Brodner G. Attenuation of the oculocardiac reflex after topically applied lignocaine during surgery for strabismus in children. Eur J Anaesthesiol. 1996;13 (1):11-15.

153. Ruta U, Gerding H, Mölhoff T. Einfluß von lokal appliziertem Lidocain auf die Auspragung des okulodardialen Reflex. Ophthalmologe. 1997;94:354-359.

154. Arnold RW, Ellis F, Wolfe T. Prolonged oculocardiac reflex during strabismus surgery under topical anesthesia. $J$ Pediatr Ophthalmol Strabismus. 1997;34(4):252-254.

155. Hakim OM, El-Hag YG, Haikal MA. Strabismus surgery under augmented topical anesthesia. J Aapos. 2005;9(3):279-284.

156. Seijas O, Liano P, Merino P, Roberts CJ. Topical anesthesia in strabismus surgery: a review of 101 cases. J Pediatr Ophthalmol Strabismus. 2009;46(4):218-222.

157. Schumacher AC, Ball M, Arnold AW, Grendahl RL, Winkle RK, Arnold RW. Oculocardiac reflex during ROP exams. Clin Ophthalmol. 2020;14:4263-4269.

158. Min SW, Hwang JM. Adjustment in patients with asystole during strabismus surgery. Graefes Arch Clin Exp Ophthalmol. 2011;249 (12):1889-1892.

159. Stump M, Arnold R. Iris color alone does not predict susceptibility to the oculocardiac reflex in strabismus surgery. Binoc Vis Strabismus Q. 1999;14(2):111-116.

160. Steward D. The oculocardiac reflex in blepharoplasty surgery. Plastic Reconstr Surg. 1989;83:249-250.

161. Matarasso A. The oculocardiac reflex in blepharoplasty surgery. Plastic Reconstruct Surg. 1989;83(2):243-248.

162. Zhang F. Clinical features of 201 cases with Duane's retraction syndrome. Chin Med J. 1997;110(10):789-791.

163. Khurana I, Sharma R, Khurana AK. Experimental study of oculocardiac reflex (OCR) with graded stimuli. Indian $J$ Physiol Pharmacol. 2006;50(2):152-156.

164. Arnold RW, Bond AN. Does Topical Proparacaine Improve Postoperative Comfort After Strabismus Surgery? Clin Ophthalmol. 2019;13:2279-2283.

165. Machida CJ, Arnold RW. The effect of induced muscle tension and fatigue on the oculocardiac reflex. Binoc Vis and Strabismus Quart. 2003;18(2):81-86.

166. Pratt L, Arnold RW. Muscle Tension and Oculocardiac Reflex: Influence of Duration and Second Muscle. Washington, DC: AAPOS; 2008.

167. Lenart TD, Lambert SR. Slipped and lost extraocular muscles. Ophthalmol Clin North Am. 2001;14(3):433-442.
168. Welters ID, Graef M, Menges T, Beikirch C, Kaufmann H, Hempelmann G. Postoperative nausea and vomiting after Faden operation. Graefes Arch Clin Exp Ophthalmol. 2000;238(1):59-63.

169. Saiah M, Borgeat A, Ruetsch YA, Seifert B, Klainguti G. Myopexy (Faden) results in more postoperative vomiting after strabismus surgery in children. Acta Anaesthesiol Scand. 2001;45 (1):59-64.

170. Cui W. [Blepharoplasty and oculocardiac reflex]. Chung Hua Cheng Hsing Shao Shang Wai Ko Tsa Chih. 1993;9(5):355-356.

171. Stott D. Reflex bradycardia in facial surgery. Br J Plast Surg. 1989;42(5):595-597.

172. Paciuc M, Mendieta G, Naranjo R. Oculocardiac reflex during laser in situ keratomileusis. J Cataract Refract Surg. 1998;24 (10):1317-1319.

173. Baykara M, Dogru M, Ozmen AT, Ozcetin H. Oculocardiac reflex in a nonsedated laser in situ keratomileusis patient. $J$ Cataract Refract Surg. 2002;28(9):1698-1699.

174. Gao L, Wang Q, Xu H, Tao Z, Wu F. The oculocardiac reflex in cataract surgery in the elderly [letter] [see comments]. $\mathrm{Br} J$ Ophthalmol. 1997;81(7):614.

175. Hampl KF, Marsch SC, Schneider M, Flammer J. Vasovagal heart block following cataract surgery under local anesthesia. Ophthalmic Surg. 1993;24(6):422-424.

176. Katz J, Feldman M, Bass E. Adverse intraoperative medical events and their association with anesthesia management strategies in cataract surgery. Ophthalmol. 2001;108(10):1721-1726.

177. Buck LS, Stockton S, Spankovich C, Jordan JR. Pediatric orbital floor fractures and the oculocardiac reflex: experience from a level I trauma center. Am J Otolaryngol. 2020;41(4):102553.

178. Ziccardi V, Russavage J, Sotereanos G, Patterson G. Oculocardiac reflex: pathophysiology and case report. Oral Surg Oral Med Oral Path. 1991;71(2):137-138.

179. Burnstine MA. Clinical recommendations for repair of orbital facial fractures. Curr Opin Ophthalmol. 2003;14(5):236-240.

180. Shearer ES, Wenstone R. Bradycardia during elevation of zygomatic fractures. A variation of the oculocardiac reflex. Anaesthesia. 1987;42(11):1207-1208.

181. Bainton R, Barnard N, Wiles JR, Brice J. Sinus arrest complicating a bitemporal approach to the treatment of pan-facial fractures. Br J Oral Maxillofac Surg. 1990;28(2):109-110.

182. Garrity JA, Yeatts RP. The oculocardiac reflex with an orbital tumor [letter]. Am J Ophthalmol. 1984;98(6):818.

183. Khan FM, Ankutse MM. Oculocardiac reflex during excision of periorbital tumor- a case report. Middle East J Anesthesiol. 1988;9(4):383-388.

184. Negrutiu S, Pop R, Cardan E. [Persistent oculocardiac reflex following retrobulbar hematoma. Case report]. Rev Chir Oncol Radiol O R L Oftalmol Stomatol Ser Oftalmol. 1988;32(2):149151.

185. Nath LS. Oculocardiac reflex. J Indian Med Assoc. 1978;71(1):910.

186. Robideaux V. Oculocardiac reflex caused by midface disimpaction. Anesthesiology. 1978;49:433.

187. Lang S, Lanigan DT. Trigeminocardiac reflexes: maxillary and mandibular variants of the oculocardiac reflex [see comments]. Can J Anaesth. 1991;38(6):757-760.

188. Campbell R, Rodrigo D, Cheung L. Asystole and bradycardia during maxillofacial surgery. Anesth Prog. 1994;41(1):13-16.

189. Shih YR, Peng SK, Tsai TC, Luk HN, Chiang CE. Repetitive junctional rhythm during forehead-lift surgery-a case report. Acta Anaesthesiol Taiwan. 2005;43(2):109-112.

190. Slade CS, Cohen SP. Elicitation of the oculocardiac reflex during endoscopic forehead lift surgery. Plast Reconstr Surg. 1999;104 (6):1828-1830. 
191. Maharaj K, Cedrola R, Mirza T. Asystole during Le Fort 1 osteotomy: the trigeminovagal reflex. Ann R Coll Surg Engl. 2020; e1-e3.

192. Green JG, Wood JM, Davis LF. Asystole after inadvertent intubation of the orbit. J Oral Maxillofac Surg. 1997;55(8):856-859.

193. Kerr W, Vance J. Oculocardiac reflex from the empty orbit. Anesthesia. 1983;38:883-885.

194. Shanks AB, O'Carroll TM. Oculocardiac reflex from an empty orbit [letter]. Anaesthesia. 1984;39(3):291-292.

195. Ginsburg R, Cartwright M, Murad S, Nelson C. Oculocardiac reflex in the anophthalmic socket. Ophthalmic Surg. 1992;23 (2):135-137.

196. Ward B, Bass S. The oculocardiac reflex in a congenitally anophthalmic child. Paediatr Anaesth. 2001;11(3):372-373.

197. Bailey PL. Sinus arrest induced by trivial nasal stimulation during alfentanil- nitrous oxide anaesthesia. Br J Anaesth. 1990;65 (5):718-720.

198. Seo K, Takayama H, Araya Y, Miura K, Someya G. A case of sinus arrest caused by opening the mouth under general anesthesia. Anesth Prog. 1994;41(1):17-18.

199. Cha ST, Eby JB, Katzen JT, Shahinian HK. Trigeminocardiac reflex: a unique case of recurrent asystole during bilateral trigeminal sensory root rhizotomy. J Craniomaxillofac Surg. 2002;30 (2):108-111.

200. Basagaoglu B, Steinberg A, Tung IT, Olorunnipa S, Maricevich RS. Oculocardiac Reflex as a Late Presentation of Orbital Floor Fracture. J Craniofac Surg. 2018;29(7):e720-e722.

201. Shakil H, Wang AP, Horth DA, Nair SS, Reddy KKV. Trigeminocardiac Reflex: case Report and Literature Review of Intraoperative Asystole in Response to Manipulation of the Temporalis Muscle. World Neurosurg. 2019;122:424-427.

202. Isenberg SJ, Blechman B. Oculocardiac reflex during postoperative muscle adjustment [letter]. Am J Ophthalmol. 1982;94 (3):422-423.

203. Eustis H. Syncopal episodes during postoperative suture adjustments in strabismus surgery: a survey. Binoc Vis Quart. 1990;5 (3):133-138.

204. Buchholz B, Kelly J, Bernatene EA, Mendez Diodati N, Gelpi RJ. Antagonistic and Synergistic Activation of Cardiovascular Vagal and Sympathetic Motor Outflows in Trigeminal Reflexes. Front Neurol. 2017;8:52.

205. Hayes RW, McBrearty E. An oculo-cardiac hypothesis of sudden unexpected death in infants. Med Hypotheses. 1979;5(4):477480.

206. Lucet V, de Bethmann O, Denjoy I. Paroxysmal vagal overactivity, apparent life-threatening event and sudden infant death. Biol Neonate. 2000;78(1):1-7.

207. Barnard NA, Bainton R. Bradycardia and the trigeminal nerve. $J$ Craniomaxillofac Surg. 1990;18(8):359-360.

208. Locke MM, Spiekermann BF, Rich GF. Trigeminovagal reflex during repair of a nasal fracture under general anesthesia. Anesth Analg. 1999;88(5):1183-1184.

209. Schaller B, Cornelius JF, Prabhakar H, et al. Trigemino-Cardiac Reflex Examination G. The trigemino-cardiac reflex: an update of the current knowledge. J Neurosurg Anesthesiol. 2009;21(3):187195.

210. Bohluli B, Schaller B, Sadr-Eshkevari P, Momen-Heravi F. Trigeminal cardiac reflex: another all-or-none law? J Oral Maxillofac Surg. 2010;68(11):2922.

211. Khurana RK. Eye examination-induced syncope Role of trigeminal afferents. Clin Auton Res. 2002;12(5):399-403.

212. Mimura T, Amano S, Funatsu H, et al. Oculocardiac reflex caused by contact lenses. Ophthalmic Physiol Opt. 2003;23 (3):263-264

213. Arnold RW. Oculocardiac reflex caused by contact lenses (letter). Ophthalmic Physiol Opt. 2003;23(6):571.
214. Javorka K, Zavarska L. [Oculocardiac reflex in premature infants]. Cesk Pediatr. 1978;33(3):138-140.

215. Clarke WN, Hodges E, Noel LP, Roberts D, Coneys M. The oculocardiac reflex during ophthalmoscopy in premature infants. Am J Ophthalmol. 1985;99(6):649-651.

216. Brown GC, Tasman WS, Naidoff M, Schaffer DB, Quinn G, Bhutani VK. Systemic complications associated with retinal cryoablation for retinopathy of prematurity. Ophthalmology. 1990;97(7):855-858.

217. de Montgolfier-aubron I, de Broca A, Kabeya B, Lego-Popesco S, Chavet MS, Gold F. [Standardized oculocardiac reflex in expremature near full term (93 cases)]. Arch Pediatr. 2002;9 (5):456-462.

218. Prakalapakorn SG, Stinnett SS, Freedman SF, Wallace DK, Riggins JW, Gallaher KJ. Non-contact retinal imaging compared to indirect ophthalmoscopy for retinopathy of prematurity screening: infant safety profile. J Perinatol. 2018;38(9):1266-1269.

219. Arnold RW, Hohberger GG, Gould AB. The oculocardiac reflex in identical twins. Arch Ophthalmol. 1988;106(7):879.

220. Hamarat Y, Bartusis L, Deimantavicius M, et al. Graphical and statistical analyses of the oculocardiac reflex during a non-invasive intracranial pressure measurement. PLoS One. 2018;13(4): e0196155.

221. Picornell-Darder I, Terzano M, Fructus X, Rostain JC, Naquet R. [The Vasalva manoeuvre and the E.E.G. in a study of professional and trainee diverse]. Rev Electroencephalogr Neurophysiol Clin. 1977;7(2):170-173.

222. Folgering H, Wijnheymer P, Geeraedts L. Diving bradycardia is not correlated to the oculocardiac reflex. Int $J$ Sports Med. 1983;4:166-169.

223. Arndt GA, Stock MC. Bradycardia during cold ocular irrigation under general anaesthesia: an example of the diving reflex [see comments]. Can J Anaesth. 1993;40(6):511-514.

224. Paton JF, Boscan P, Pickering AE, Nalivaiko E. The yin and yang of cardiac autonomic control: vago-sympathetic interactions revisited. Brain Res Brain Res Rev. 2005;49(3):555-565.

225. Pillunat L, Stodtmeister R, Marquardt R. [Ocular hemodynamics following suction cup oculoression]. Klin Monats Augenheilkunde. 1988;193(5):476-480.

226. Kurmyshkin AA, Kurmyshkin NA. [Activation of the heart rhythm during negative compression of the eyeballs in healthy subjects]. Fiziol Zh SSSR Im I M Sechenova. 1992;78(6):64-69.

227. de Broca A, Kremp O, Krim G, Herbaut C, Leke L, Risbourg B. [Standardization of oculo-cardiac reflex in infants under 3 months of age]. Pediatrie. 1990;45(6):405-408.

228. Reyners AK, Tio RA, Vlutters FG, van der Woude GF, Reitsma WD, Smit AJ. Re-evaluation of the cold face test in humans. Eur J Appl Physiol. 2000;82(5-6):487-492.

229. Ducrocq J, Cardot V, Tourneux P, Chardon K, Telliez F, Libert JP. Use of the oculocardiac reflex to assess vagal reactivity during quiet sleep in neonates. J Sleep Res. 2006;15(2):167-173.

230. Schipke JD, Siegmund K, Taher A, et al. Loss of consciousness via oculocardiac reflex during deep breath-hold diving. A case report. Int J Cardiol. 2015;193:56-57.

231. Maltsev VA, Lakatta EG. A novel quantitative explanation for the autonomic modulation of cardiac pacemaker cell automaticity via a dynamic system of sarcolemmal and intracellular proteins. $\mathrm{Am} J$ Physiol Heart Circ Physiol. 2010;298(6):H2010-2023.

232. Marcus B, Gillette PC, Garson A. Intrinsic heart rate in children and young adults: an index of sinus node function isolated from autonomic control. Am Heart J. 1990;119(4):911-916.

233. Fessl-Alemany E, Stocker L, Taube HD, Wessing A. [General anaesthesia in ophthalmic surgery. 5 year report from the eye hospital Essen]. Klin Monbl Augenheilkd. 1973;162(2):254262. 
234. Apivor D, Ravi PK, Little L. Cardiac effects of intravenous atropine. Electrocardiographic studies during ketamine anaesthesia. Anaesthesia. 1978;33(6):542-545.

235. Ge XY. [Two methods of mitigating the oculo-cardiac reflex during ocular muscle surgery under general anesthesia]. Chung Hua Yen Ko Tsa Chih. 1984;20(3):148-149.

236. Ge XY. [The oculocardiac reflex of children during extraocular muscle operation under general anesthesia (report of 60 cases)]. Chung Hua Yen Ko Tsa Chih. 1982;18(4):218-219.

237. Grover VK, Bhardwaj N, Shobana N, Grewal SP. Oculocardiac reflex-peribulbar block or opioid-relaxant anaesthesia [letter]. Can J Anaesth. 1998;45(7):706.

238. Fry E. Prevention of the oculocardiac reflex in children undergoing squint surgery. Brit J Ophthal. 1983;55:256.

239. Apt L, Isenberg S. The oculocardiac reflex as a surgical aid in identifying a slipped or 'lost' extraocular muscle. $\mathrm{Br} J$ Ophthalmol. 1980;64:362-365.
240. Apt L, Isenberg S. Oculocardiac Reflex. Brit J Ophthal. 1981;65:590.

241. Meuwly C, Golanov E, Chowdhury T, Erne P, Schaller B Trigeminal cardiac reflex: new thinking model about the definition based on a literature review. Medicine. 2015;94(5):e484.

242. Blanc VF. Anticholinergic premedication for infants and children (the oculocardiac reflex) [letter]. Can Anaesth Soc J. 1983;30 (6):683-684.

243. Blanc VF. Ventilation and the oculocardiac reflex [letter]. Anaesthesia. 1987;42(3):324-326.

244. Braun GG, Schywalsky M, Naujoks B, Brunner M, Danner U, Hauschild S. Atropin versus Glycopyrrolat bei ophthalmochirurgischen Eingriffen. Anaesthesiol Reanimat. 1992;17:57-65.

245. Yamashita M. [Oculocardiac reflex and anesthesia]. Masui. 1985;35(1):2-11

246. Yamashita M. Oculocardiac reflex and the anesthesiologist. Mid East J Anesthesiology. 1986;8(5):399-415.
Clinical Ophthalmology

\section{Publish your work in this journal}

Clinical Ophthalmology is an international, peer-reviewed journal covering all subspecialties within ophthalmology. Key topics include: Optometry; Visual science; Pharmacology and drug therapy in eye diseases; Basic Sciences; Primary and Secondary eye care; Patient Safety and Quality of Care Improvements. This journal is indexed on PubMed

Submit your manuscript here: https://www.dovepress.com/clinical-ophthalmology-journal
Dovepress

Central and CAS, and is the official journal of The Society of Clinical Ophthalmology (SCO). The manuscript management system is completely online and includes a very quick and fair peer-review system, which is all easy to use. Visit http://www.dovepress.com/ testimonials.php to read real quotes from published authors. 